\title{
Histone deacetylase inhibitor-induced cell death in bladder cancer is associated with chromatin modification and modifying protein expression: A proteomic approach
}

\author{
QINGDI QUENTIN LI ${ }^{1}$, JIAN-JIANG HAO ${ }^{2}$, ZHENG ZHANG ${ }^{2}$, IAWEN HSU ${ }^{1}$, YI LIU ${ }^{2}$, ZHEN TAO $^{2}$, \\ KEIDREN LEWI ${ }^{1}$, ADAM R. METWALLI ${ }^{1}$ and PIYUSH K. AGARWAL ${ }^{1}$ \\ ${ }^{1}$ Urologic Oncology Branch, Center for Cancer Research, National Cancer Institute, \\ National Institutes of Health, Bethesda, MD 20892; ${ }^{2}$ Poochon Scientific, Frederick, MD 21704, USA
}

Received February 6, 2016; Accepted March 17, 2016

DOI: 10.3892/ijo.2016.3478

\begin{abstract}
The Cancer Genome Atlas (TCGA) project recently identified the importance of mutations in chromatin remodeling genes in human carcinomas. These findings imply that epigenetic modulators might have a therapeutic role in urothelial cancers. To exploit histone deacetylases (HDACs) as targets for cancer therapy, we investigated the HDAC inhibitors (HDACIs) romidepsin, trichostatin A, and vorinostat as potential chemotherapeutic agents for bladder cancer. We demonstrate that the three HDACIs suppressed cell growth and induced cell death in the bladder cancer cell line 5637. To identify potential mechanisms associated with the antiproliferative and cytotoxic effects of the HDACIs, we used quantitative proteomics to determine the proteins potentially involved in these processes. Our proteome studies identified a total of 6003 unique proteins. Of these, 2472 proteins were upregulated and 2049 proteins were downregulated in response to HDACI exposure compared to the untreated controls $(\mathrm{P}<0.05)$. Bioinformatic analysis further revealed that those differentially expressed proteins were involved in multiple biological functions and enzyme-regulated pathways, including cell cycle progression, apoptosis, autophagy, free radical generation and DNA damage repair. HDACIs also altered the acetylation status of histones and non-histone proteins, as well as the levels of chromatin modification proteins, suggesting that HDACIs exert multiple cytotoxic actions in bladder cancer cells by inhibiting HDAC activity or altering the structure of chromatin. We conclude that HDACIs are effective in the inhibition of cell proliferation and the
\end{abstract}

Correspondence to: Dr Qingdi Quentin Li or Dr Piyush K. Agarwal, National Institutes of Health, Bethesda, MD 20892, USA

E-mail: liquenti@mail.nih.gov

E-mail: agarwalpk2@mail.nih.gov

Key words: apoptosis, bladder cancer, HDAC inhibitor, proteomics, pathway analysis, cell cycle, DNA damage repair induction of apoptosis in the 5637 bladder cancer cells through multiple cell death-associated pathways. These observations support the notion that HDACIs provide new therapeutic options for bladder cancer treatment and thus warrant further preclinical exploration.

\section{Introduction}

Urinary bladder cancer is the second most common malignant tumor of the genitourinary tract and ranks fourth among male cancers (1). Approximately $70 \%$ of initially diagnosed tumors are superficial and can be treated by transurethral resection, while the remaining $30 \%$ become muscle invasive and are associated with a high risk of metastatic disease $(2,3)$. Systemic chemotherapy is a treatment option for patients with locally advanced or metastatic disease. Despite huge efforts to tackle the disease in the past two decades, current treatments confer only a modest survival benefit upon bladder cancer patients, and long-term survival of patients suffering from metastatic disease does not exceed $20 \%$ (4); therefore, there is an urgent need for innovative ideas that deviate from conventional approaches.

The search for novel chemical agents against cancer has long been the mainstay of cancer research. During recent years, it has been shown that epigenetic aberrations are involved in tumorigenesis. Particularly, an imbalance in the equilibrium between histone acetylation and histone deacetylation has been proposed as a driving force, causing normal cells to become malignant. Therefore, modulating acetylation may be an innovative strategy to treat malignant disease. Acetylation is catalyzed by a specific enzyme family, histone acetyltransferases (HATs), and correlates with nucleosome remodeling and transcriptional activation, whereas deacetylation of histone tails is catalyzed by histone deacetylases (HDACs) and induces transcriptional repression through chromatin condensation (5).

Altered expression of different HDACs has been reported in various human cancers (6-12). Systemic analysis of the expression levels of HDACs in cultured cancer cell lines, as well as primary cultures of human cancer cells and various human tumor biopsy samples, frequently identifies higher levels of 
expression than in corresponding normal tissue. For instance, recent evidence shows that both clinical samples from patients with urinary bladder cancer and tumor tissues from a mouse model have demonstrated a significantly increased HDAC expression compared with surrounding healthy tissue (13). Thus, HDAC inhibition might be an effective option to treat bladder cancer.

Thus far, 18 HDACs have been identified in mammals that are classified into four classes based on their homology to yeast proteins $(7,14)$. Class I HDAC enzymes (HDACs $1,2,3$ and 8$)$ are widely expressed $(12,15)$, class II HDAC enzymes (HDACs 4, 5, 6, 7, 9 and 10) have tissue-specific distribution and are involved in organ development and function (12), and other classes are less specific in terms of tissue distribution and function. HDAC inhibitors (HDACIs) prevent HDACs from removing acetyl groups, leading to increased acetylation and allowing DNA to remain transcriptionally active (5). There are many known natural and synthetic HDACIs, which can be subdivided into five structural classes, including hydroxamates, cyclic peptides, aliphatic acids, benzamines and electrophilic ketones. The hydroxamate compound trichostatin A (TSA) is a potent nanomolar inhibitor of most class I and class II HDAC enzymes $(12,16)$. Romidepsin (FK228) is the only cyclic peptide HDACI in clinical development $(17,18)$, and it potently inhibits class I HDACs $(12,18)$. Class I HDAC enzymes are overexpressed in many malignancies, and this overexpression is often associated with poor prognosis (12). A number of structurally different HDACIs are in clinical trials for a wide variety of hematologic and solid neoplasms, including cancer of the lung, breast, pancreas, and kidney, melanoma, glioblastoma, leukemias, lymphomas and multiple myeloma (5). Among them, romidepsin and vorinostat (SAHA) have been approved by the Food and Drug Administration for the treatment of cutaneous T-cell lymphoma (CTCL). However, the effect and the mechanism of action of HDACIs as chemotherapeutic regimens for bladder cancer remain to be determined.

Herein, we show that the treatment with HDACIs (romidepsin, TSA and SAHA) inhibited cell growth and proliferation in a dose-dependent fashion in the urinary bladder cancer cell line 5637. We further analyzed the protein expression patterns in response to romidepsin and TSA in this cell model system using quantitative proteomic studies and found that the effect of these two HDACIs on growth inhibition and cell death is mediated through modulating the expression of proteins involved in cell cycle progression, apoptosis, autophagy, reactive oxygen species (ROS) generation and DNA damage repair in 5637 bladder cancer cells.

\section{Materials and methods}

Chemicals and reagents. The minimum essential medium (MEM), fetal bovine serum (FBS), penicillin-streptomycin (100X), and $0.25 \%$ trypsin-EDTA solution (1X) were obtained from Invitrogen Corp., Life Technologies (Carlsbad, CA, USA). Trichostatin A (TSA) (>98\% purity) was from Selleckchem (Houston, TX, USA). Romidepsin (FK228) (>98\% purity) was purchased from Apexbio Technology LLC (Houston, TX, USA). Vorinostat (SAHA) and dimethyl sulfoxide (DMSO) were from Sigma-Aldrich (St. Louis, MO, USA). Romidepsin,
TSA or SAHA were dissolved in DMSO separately and stored at $-20^{\circ} \mathrm{C}$. The CellTiter 96 AQueous One Solution Cell Proliferation Assay was from Promega Corp. (Madison, WI, USA).

Cell culture and cell viability assay. The human bladder cancer cell line 5637 was purchased from the American Type Culture Collection (ATCC; Manassas, VA, USA). The cell line was grown in MEM, supplemented with $10 \% \mathrm{FBS}, 50 \mathrm{IU} / \mathrm{ml}$ penicillin, and $50 \mu \mathrm{g} / \mathrm{ml}$ streptomycin, at $37^{\circ} \mathrm{C}$ in a humidified atmosphere with $5 \% \mathrm{CO}_{2}$.

The antiproliferative effects of romidepsin, TSA and SAHA were assessed using an MTS (3-(4,5-dimethylthiazol-2-yl)-5(3-carboxymethoxyphenyl)-2-(4-sulfophenyl)-2H-tetrazolium)based assay (Promega) as previously described (19). In brief, 5637 bladder carcinoma cells $\left(5 \times 10^{3}\right.$ cells/well) were evenly distributed in 96-well plates, grown overnight, and then treated with various concentrations of romidepsin, TSA or SAHA at the indicated concentrations $(0,0.11,10$ and $100 \mathrm{nM}, 1,10$ and $100 \mu \mathrm{M}$ ) for 24 or $72 \mathrm{~h}$. At the end of incubation, $20 \mu \mathrm{l}$ of CellTiter 96 AQueous One Solution reagent was added to each well of the assay plates containing the treated and untreated cells in $200 \mu \mathrm{l}$ of culture medium, and the plates were incubated at $37^{\circ} \mathrm{C}$ and $5 \% \mathrm{CO}_{2}$ for $2 \mathrm{~h}$. The optical density at $490 \mathrm{~nm}$ was determined using a 96-well iMark ${ }^{\mathrm{TM}}$ Microplate reader (Bio-Rad Laboratories, Hercules, CA, USA). Proliferation rates were calculated from the optical densities of the HDACItreated cells relative to the optical density of DMSO-treated control cells with no HDACI exposure (control value, 100\%). The half-maximal inhibitory concentration $\left(\mathrm{IC}_{50}\right)$ values for romidepsin, TSA and SAHA on 24 and $72 \mathrm{~h}$ in 5637 cell line were calculated using GraphPad Prism version 6.01 software (GraphPad Software, Inc., La Jolla, CA, USA). IC 50 was considered as the drug concentration that decreases the cell count by $50 \%$. Non-linear regression curve fitting was performed. The data were fitted to an exponential first-order decay function.

Preparation of protein extraction, separation of proteins and in-gel trypsin digestion. Total protein extraction from cell pellets was prepared by the following method. In brief, cell pellets were lysed in $0.4 \mathrm{ml}$ lysis buffer $(20 \mathrm{mM}$ Tris- $\mathrm{HCl}$, pH 7.5, $150 \mathrm{mM} \mathrm{NaCl}, 1 \mathrm{mM} \mathrm{Na}{ }_{2}$ EDTA, 1 mM EGTA, $1 \%$ Triton X-100, protease inhibitor cocktail pill). After cells were lysed, $50 \mu \mathrm{l}$ of $10 \% \mathrm{SDS}$ and $50 \mu \mathrm{l}$ of $1 \mathrm{MDTT}$ were added into the mixture followed by incubation at $95^{\circ} \mathrm{C}$ for $10 \mathrm{~min}$. The extraction was then sonicated and centrifuged at $15,000 \mathrm{x} g$ for $10 \mathrm{~min}$. Supernatants were collected and stored at $-80^{\circ} \mathrm{C}$ for further analysis. The protein concentration of the supernatants was determined by a $\mathrm{BCA}^{\mathrm{TM}}$ reducing reagent compatible assay kit (Thermo Fisher Scientific, Rockford, IL, USA).

Equal amounts of protein $(130 \mu \mathrm{g})$ from each sample were fractioned by separation on a NuPAGE 4-12\% Bis-Tris Gel (Life Technologies, Grand Island, NY, USA). Sixteen gel fractions from each lane representing one sample were treated with DTT for reduction, then iodoacetamide for alkylation, and further digested by trypsin in $25 \mathrm{mM}$ $\mathrm{NH}_{4} \mathrm{HCO}_{3}$ solution. The digested protein was extracted, and the extracted peptides were dried and reconstituted in $20 \mu \mathrm{l}$ of $0.1 \%$ formic acid before nanospray LC/MS/MS analysis was performed. 
Nanospray LC/MS/MS analysis. Sixteen tryptic peptide fractions from one cell sample were analyzed sequentially using a Thermo Scientific Q Exactive Hybrid Quadrupole-Orbitrap mass spectrometer equipped with a Thermo Dionex UltiMate 3000 RSLCnano system. Tryptic peptide samples were loaded onto a peptide trap cartridge at a flow rate of $5 \mu \mathrm{l} / \mathrm{min}$. The trapped peptides were eluted onto a reversed-phase $25-\mathrm{cm} \mathrm{C18}$ Picofrit column (New Objective, Woburn, MA, USA) using a linear gradient of acetonitrile (3-36\%) in $0.1 \%$ formic acid. The elution duration was $110 \mathrm{~min}$ at a flow rate of $0.3 \mu \mathrm{l} / \mathrm{min}$. Eluted peptides from the Picofrit column were ionized and sprayed into the mass spectrometer, using a Nanospray Flex Ion Source ES071 (Thermo Fisher Scientific) under the following settings: spray voltage, $1.6 \mathrm{kV}$ and capillary temperature, $250^{\circ} \mathrm{C}$. The Q Exactive instrument was operated in the data dependent mode to automatically switch between full scan MS and MS/MS acquisition. Survey full scan MS spectra (m/z 300-2000) was acquired in the Orbitrap with 70,000 resolution $(\mathrm{m} / \mathrm{z} 200)$ after accumulation of ions to a $3 \times 10^{6}$ target value based on predictive AGC from the previous full scan. Dynamic exclusion was set to $20 \mathrm{sec}$. The 12 most intense multiply-charged ions $(\mathrm{z} \geq 2)$ were sequentially isolated and fragmented in the Axial higher energy collision-induced dissociation (HCD) cell using normalized HCD collision energy at $25 \%$ with an AGC target 1e5 and a maxima injection time of $100 \mathrm{~ms}$ at 17,500 resolution.

LC/MS/MS data analysis. The raw MS files were analyzed using the Thermo Proteome Discoverer 1.4.1 platform (Thermo Fisher Scientific, Bremen, $\mathrm{GmbH}$ ) for peptide identification and protein assembly. For each cell sample, 16 raw MS files obtained from 16 sequential LC/MS analyses were grouped for a single database search against the Human UniProtKB/Swiss-Prot human protein sequence databases (20597 entries, 12/20/2013) based on the SEQUEST and percolator algorithms through the Proteome Discoverer 1.4.1 platform. Carbamidomethylation of cysteines was set as a fixed modification. The minimum peptide length was specified to be five amino acids. The precursor mass tolerance was set to $15 \mathrm{ppm}$, whereas fragment mass tolerance was set to $0.05 \mathrm{kDa}$. The maximum false peptide discovery rate was specified as 0.01. The resulting Proteome Discoverer Report contains all assembled proteins (a proteome profile) with peptides sequences and matched spectrum counts. Three proteome profiles were generated for the untreated control cells and two HDACI-treated cell samples.

Protein quantification. Protein quantification used the normalized spectral abundance factors (NSAFs) method to calculate the protein relative abundance $(20,21)$. To quantitatively describe the relative abundance, the ppm (part per million) was chosen as the unit and the $1,000,000 \mathrm{ppm}$ value was assigned to each proteome profile. A ppm value at the range of $0-1,000,000 \mathrm{ppm}$ for each identified protein in each proteome profile was calculated based on its normalized NSAF.

The ppm was calculated as follows: $\mathrm{RC}_{\mathrm{N}}=10^{6} \times \mathrm{NSAF}_{\mathrm{N}}$, where $\mathrm{RC}_{\mathrm{N}}$ is the relative concentration of protein $\mathrm{N}$ in the proteome of test sample, $\mathrm{NSAF}_{\mathrm{N}}$ is the protein's normalized spectral abundance factor and $\mathrm{N}$ is the protein index.
NSAFs were calculated as follows: $\operatorname{NSAF}_{N}=\left(\mathrm{S}_{\mathrm{N}} / \mathrm{L}_{\mathrm{N}}\right) /$ $\left(\Sigma_{\mathrm{ni}}={ }_{1} \mathrm{~S}_{\mathrm{i}} / \mathrm{L}_{\mathrm{i}}\right)$, where $\mathrm{N}$ is the protein index, $\mathrm{S}_{\mathrm{N}}$ is the number of peptide spectra matched to the protein, $\mathrm{L}_{\mathrm{N}}$ is the length of protein $\mathrm{N}$ (number of amino acid residues), and $\mathrm{n}$ is the total number of proteins in the input database (proteome profile for one cell sample). The ratio of HDACI treated vs. untreated control was defined as 1,000 if the protein was not identified in untreated control, or as 0.001 if the protein was not identified in HDACI-treated sample.

Signaling pathway analysis. The cell functions are executed and regulated by the entire sets of proteins (the proteome). The regulation of different cellular functions has been categorized into a number of pathways, such as cell cycle and apoptosis signaling pathways. In each pathway, the components according to their functions are generally named as ligands, receptors, activating regulators, inhibitory regulators and effectors. In order to measure the activation strength of a pathway, the protein molecules that belong to ligands, receptors, activating regulators, inhibitory regulators, or effectors were grouped and their relative abundances ( $\mathrm{ppm}$ ) were summed. The protein list for all analyzed pathways and processes was obtained from the Kyoto Encyclopedia of Genes and Genomes (KEGG) pathway database (http://www.genome.jp/kegg/pathway.html), and their functional annotations were manually confirmed using the UniProtKB protein database and the NCBI protein database or available publications.

Statistical data analysis. All quantitative values are presented as means $\pm \mathrm{SD}$. Data were statistically analyzed using two-way analysis of variance (ANOVA) for comparison among groups. Student's t-test was used to analyze the statistical significance of differences between untreated controls and HDACI-treated groups. All P-values were determined using a two-sided test, and P-values $<0.05$ were considered to indicate significance.

\section{Results}

HDACIs inhibit cell proliferation and induce cytotoxicity in human bladder cancer cells. To investigate the effect of HDACIs on bladder cancer cell growth and proliferation, we selected human bladder cancer 5637 cells, a cell line commonly used as a model for studying bladder carcinoma. The dose-response of romidepsin, TSA and SAHA inhibition of the growth of 5637 cell line was characterized in vitro using the MTS assay. Romidepsin, TSA or SAHA at concentrations of $0.1 \mathrm{nM}$ to $100 \mu \mathrm{M}$ caused dose-dependent inhibition of the proliferation of 5637 cells at $72 \mathrm{~h}$ (Fig. 1A). The half-maximal inhibitory concentration $\left(\mathrm{IC}_{50}\right)$ values of romidepsin, TSA and SAHA at $72 \mathrm{~h}$ in this line were $1.0 \pm 0.1 \mathrm{nM}, 100 \pm 3.5 \mathrm{nM}$ and $1.9 \pm 0.1 \mu \mathrm{M}$, respectively. These results indicate that HDACIs can potently inhibit cell proliferation and induce cell toxicity in bladder cancer cells.

Previous study has demonstrated that HDACIs increase histone acetylation levels in human bladder cancer cells and that these levels peak at $24 \mathrm{~h}$ and decrease gradually over 48-72 $\mathrm{h}$ (22). Therefore, we chose 24-h treatment with HDACIs for this in vitro study. To establish the appropriate HDACI treatment concentration for our proteomic studies, we performed cytotoxicity assays in 5637 cells in response to romidepsin, 

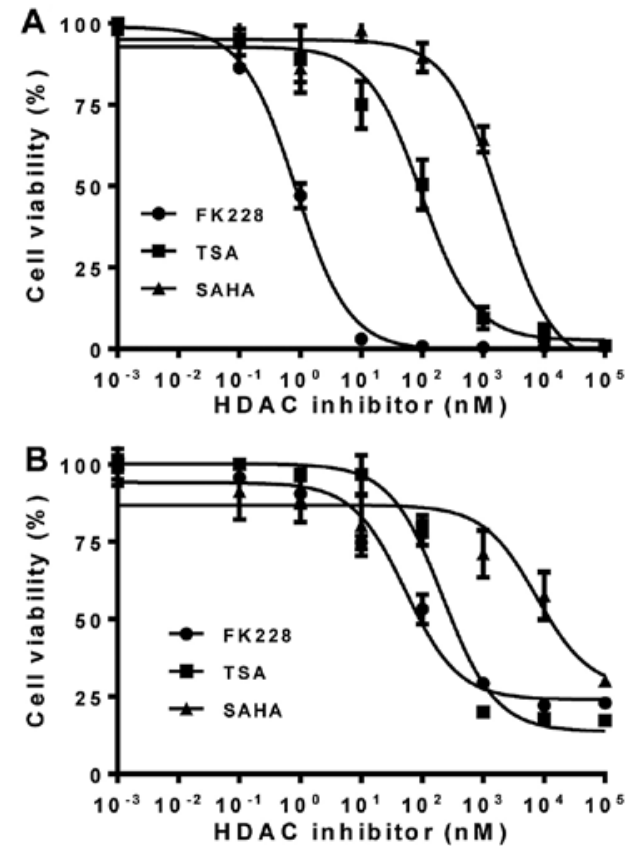

Figure 1. Histone deacetylase inhibitors (HDACIs) suppress cell proliferation and induce cytotoxicity in human bladder cancer 5637 cells. Cells (5637) were evenly distributed in 96 -well plates $\left(5 \times 10^{3}\right.$ cells/well) and treated for $72 \mathrm{~h}$ (A) or $24 \mathrm{~h}$ (B) with romidepsin (FK228), trichostatin A (TSA), or vorinostat (SAHA) at the indicated concentrations. The ability of HDACIs to inhibit cell growth and proliferation was determined by the MTS assay, as described in Materials and methods. Cell viability values are expressed relative to those for cells with no HDACI exposure (control value, 100\%). The results represent the means $\pm \mathrm{SD}$ of three independent experiments. MTS, 3-(4,5-dimethylthiazol-2-yl)-5-(3-carboxymethoxyphenyl)-2-(4sulfophenyl)-2H-tetrazolium.

TSA or SAHA treatment at different concentrations. As shown in Fig. 1B, with dose-increased HDACI treatment for $24 \mathrm{~h}$, the viability of 5637 cells correspondingly decreased, and the romidepsin, TSA and SAHA working concentrations resulting in $50 \%$ cell viability were $50 \pm 3.5 \mathrm{nM}, 200 \pm 20 \mathrm{nM}$ and $7.5 \pm 0.5 \mu \mathrm{M}$, respectively. Since the activity of romidepsin and TSA was much more potent than SAHA in cytotoxicity in 5637 cells (Fig. 1), we therefore, finally used the working concentrations of 50 and $200 \mathrm{nM}$ for 24-h treatment for romidepsin and TSA, respectively, for the following proteomic experiments.

Quantitative proteomic analysis of bladder cancer cells following HDACI treatment. To analyze the mechanisms responsible for the effect of HDACIs on cell proliferation and cytotoxicity in bladder cancer cells, the whole cell proteome profiles of the HDACI-treated and untreated 5637 cells were compared using quantitative proteomic studies. Differentially expressed proteins were identified and quantified by nanospray LC/MS/MS mass spectrometry. The selection criteria for deregulation were the same for all the samples: identification based on at least two unique peptides and fold difference $>2.0$ or $<-2.0$.

Using the nanospray LC/MS/MS analysis, a total of 6003 non-redundant proteins were identified in both HDACI treated and untreated 5637 cells. Of these, 4865, 4618 and 4674 were quantified in romidepsin-treated, TSA-treated and untreated cells, respectively. A total of 3518 proteins were common to the two HDACI-treated cells and untreated cells.
Compared with the untreated control, there were 5698 differentially expressed proteins in romidepsin-treated 5637 cells, including 2969 upregulated proteins (1845 $\geq 2$-fold upregulated proteins) and 2729 downregulated proteins (1626 $\geq 2$-fold downregulated proteins). The fold changes ranged from 45.51 to -35.99 and 1979 of these proteins (both upregulated and downregulated proteins) showed $>10$-fold deregulation. For the TSA-treated 5637 cells, a total of 5497 proteins were differentially regulated; 2808 were upregulated (1709 $\geq 2$-fold upregulated) and 2689 downregulated (1563 $\geq 2$-fold downregulated). The fold changes ranged from 36.18 to -26.83 and 1826 of these proteins (both upregulated and downregulated proteins) showed more than 10 -fold deregulation. A total of $1082 \geq 2$-fold upregulated proteins and $1140 \geq 2$-fold downregulated proteins were common to both romidepsin-treated and TSA-treated 5637 cells.

Functional classification of differentially expressed proteins in HDACI-treated bladder cancer cells. To gain an initial understanding of the role and function of the identified proteins between the HDACI treated and untreated 5637 bladder cancer cells, we merged the protein datasets and used pathway software to provide a descriptive analysis. The functional correlation analysis of the differentially regulated proteins was done by database search using UniProt, Swiss-Prot and PANTHER. The categorization of differentially expressed proteins ( $\geq 2$-fold upregulated and downregulated proteins) according to their molecular function, biological process and cellular component is shown in Fig. 2. These data are based on a compilation of proteins from the romidepsin-treated cell samples and are presented to demonstrate the range of molecular functions (Fig. 2A) and biological processes (Fig. 2B) represented by the identified proteins, and the cellular component (Fig. 2C) to which the proteins belong. According to cellular component, the analysis revealed a high percentage of proteins corresponding to the cell part, organelle, macromolecular complex, extracellular region and extracellular matrix (Fig. 2C). Based on molecular function, the most general categories of proteins were catalytic activity, binding activity, structural molecule activity, nucleic acid transcription factor activity, enzyme regulator activity, transporter activity and receptor activity (Fig. 2A). Differentially expressed proteins related to 13 biological processes, including metabolic process, cellular process, localization, biological regulation, developmental process, cellular component organization or biogenesis, response to stimulus and apoptotic process (Fig. 2B).

A majority of the molecular functions and biological processes were affected in both romidepsin-treated and TSA-treated bladder cancer cells. Although romidepsin caused more differentially expressed proteins ( $3471 \geq 2$-fold upregulated and downregulated) than those caused by TSA (3272 $\geq 2$-fold upregulated and downregulated proteins), the percentages of proteins in each category of the molecular function and biological process were similar between the romidepsin-treated (Fig. 2A and B) and TSA-treated (data not shown) 5637 cells. There were 1845 and $1709 \geq 2$-fold upregulated proteins and 1626 and $1563 \geq 2$-fold downregulated proteins in romidepsin-treated and TSA-treated cell samples, respectively. We also compared and showed that in either the upregulated proteins or the downregulated proteins, there was 


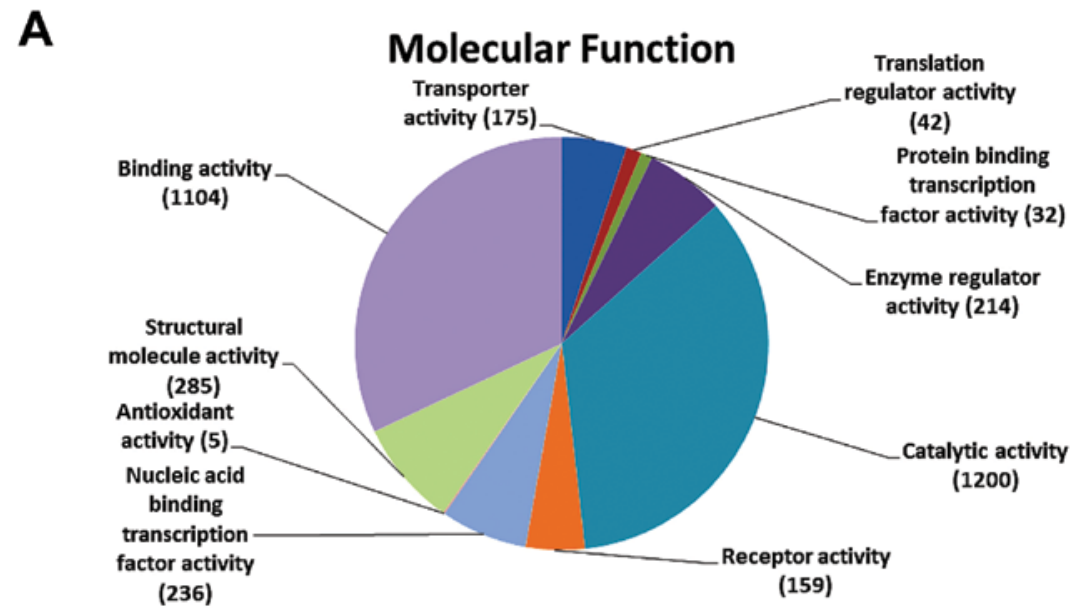

B 
Table I. Main metabolic and enzymatic pathways associated with the upregulated and downregulated proteins in romidepsintreated 5637 cells as analyzed by the Kyoto Encyclopedia of Genes and Genomes. ${ }^{a}$

\begin{tabular}{|c|c|c|c|}
\hline Biological pathway & $\%$ & P-value & Benjamini \\
\hline \multicolumn{4}{|l|}{$1845 \geq 2$-fold upregulated proteins } \\
\hline Ribosome & 1.8 & $4.0 \times 10^{-9}$ & $7.1 \times 10^{-7}$ \\
\hline Oxidative phosphorylation & 2.1 & $5.8 \times 10^{-7}$ & $3.4 \times 10^{-5}$ \\
\hline Ubiquitin mediated proteolysis & 2.0 & $6.1 \times 10^{-6}$ & $2.1 \times 10^{-4}$ \\
\hline Lysosome & 1.5 & $7.1 \times 10^{-4}$ & $1.5 \times 10^{-2}$ \\
\hline Amino sugar and nucleotide sugar metabolism & 0.8 & $1.3 \times 10^{-3}$ & $2.2 \times 10^{-2}$ \\
\hline Mismatch repair & 0.5 & $6.8 \times 10^{-3}$ & $8.8 \times 10^{-2}$ \\
\hline Basal transcription factors & 0.6 & $7.6 \times 10^{-3}$ & $9.1 \times 10^{-2}$ \\
\hline DNA replication & 0.6 & $9.3 \times 10^{-3}$ & $1.0 \times 10^{-2}$ \\
\hline Nucleotide excision repair & 0.6 & $3.3 \times 10^{-2}$ & $2.8 \times 10^{-2}$ \\
\hline Purine metabolism & 1.5 & $4.1 \times 10^{-2}$ & $3.2 \times 10^{-2}$ \\
\hline Pyrimidine metabolism & 1.0 & $6.2 \times 10^{-2}$ & $4.0 \times 10^{-2}$ \\
\hline RNA polymerase & 0.4 & $6.2 \times 10^{-2}$ & $3.9 \times 10^{-2}$ \\
\hline \multicolumn{4}{|l|}{$1626 \geq 2$-fold downregulated proteins } \\
\hline $\mathrm{N}$ - and O-Glycan biosynthesis & 1.3 & $5.4 \times 10^{-5}$ & $1.2 \times 10^{-4}$ \\
\hline Glycerophospholipid metabolism & 1.0 & $4.7 \times 10^{-3}$ & $1.5 \times 10^{-2}$ \\
\hline Cell cycle & 1.4 & $4.8 \times 10^{-3}$ & $1.3 \times 10^{-2}$ \\
\hline Lysine degradation & 0.7 & $1.1 \times 10^{-2}$ & $2.0 \times 10^{-2}$ \\
\hline Valine, leucine and isoleucine degradation & 0.6 & $3.2 \times 10^{-2}$ & $3.8 \times 10^{-2}$ \\
\hline Glycerolipid metabolism & 0.6 & $3.6 \times 10^{-2}$ & $3.9 \times 10^{-2}$ \\
\hline Sphingolipid metabolism & 0.5 & $4.7 \times 10^{-2}$ & $4.1 \times 10^{-2}$ \\
\hline Biosynthesis of unsaturated fatty acids & 0.4 & $3.2 \times 10^{-2}$ & $3.1 \times 10^{-2}$ \\
\hline Steroid biosynthesis & 0.3 & $5.3 \times 10^{-2}$ & $4.0 \times 10^{-2}$ \\
\hline Bladder cancer & 0.5 & $6.6 \times 10^{-2}$ & $4.1 \times 10^{-2}$ \\
\hline Ether lipid metabolism & 0.5 & $7.6 \times 10^{-2}$ & $4.3 \times 10^{-2}$ \\
\hline Methane metabolism & 0.2 & $8.8 \times 10^{-2}$ & $4.7 \times 10^{-2}$ \\
\hline
\end{tabular}

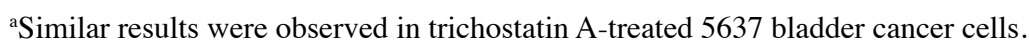

KEGG database by DAVID bioinformatics resources tool (DAVID v6.7, the Database for Annotation, Visualization and Integrated Discovery) showed that the downregulated proteins were associated with multiple pathways, such as cell cycle, bladder cancer, lysine degradation, valine, leucine, and isoleucine degradation, and all major annotated lipid metabolism pathways including glycerophospholipid metabolism, steroid biosynthesis, glycerolipid metabolism, sphingolipid metabolism and ether lipid metabolism (Table I). We also performed the same analysis for HDACI upregulated proteins, which were enriched in the DNA replication and nucleotide related processes, including ribosome, amino sugar and nucleotide sugar metabolism, mismatch repair, basal transcription factors, nucleotide excision repair, purine metabolism, pyrimidine metabolism and RNA polymerase (Table I).

HDACI-induced cell death in bladder cancer cells is mediated via modulating cell cycle progression, apoptosis and DNA damage repair. Given that HDACIs have been shown to exert a variety of anticancer activities in different types of tumors and that both romidepsin and TSA induced cell growth inhibition and cell death in our bladder cancer cells
(Fig. 1), we elucidated the mechanism underlying the effect of HDACIs on cell proliferation and cytotoxicity in this model system. We performed pathway-clustering analyses of the HDACI-responsive proteome for pathways involved in cell death. The results showed that cell cycle, apoptosis, oxidative stress, autophagy, and DNA damage repair were the most prominent pathways enriched with altered protein levels in HDACI-treated cells (Fig. 3), suggesting that these pathways are involved in HDACI-induced cell death in 5637 bladder cancer cells.

To understand more about the mechanisms of HDACIinduced cell death in our bladder cancer cell model, we identified the differentially expressed proteins related to cell death in these pathways in response to HDACI treatment. Table II shows part of the differentially expressed proteins involved in cell death in both romidepsin and TSA treated cells. These include 37 proteins involved in cell cycle progression, 19 proteins associated with apoptosis process, 30 proteins in various DNA damage repair pathways and 11 proteins involved in ROS generation and autophagy regulation. The functions and levels of the proteins in each pathway are listed in the table. 
Table II. Alterations in the levels of the proteins associated with cell death in bladder cancer cells in response to romidepsin or trichostatin A (TSA) treatment.

Protein level (ppm)

Accession no.

Protein name

Symbol Protein function

Untreated Romidepsin TSA

Regulation of cell cycle

\begin{tabular}{|c|c|c|c|c|c|c|}
\hline 116176 & G2/mitotic-specific cyclin-B1 & CCNB1 & Cyclin & 7.19 & 0 & 0 \\
\hline 5921731 & G2/mitotic-specific cyclin-B2 & $\mathrm{CCNB} 2$ & Cyclin & 7.83 & 0 & 0 \\
\hline 218511966 & Cyclin-K & CCNK & Cyclin & 37.57 & 23.28 & 7.47 \\
\hline 74753368 & Cyclin-L1 & CCNL1 & Cyclin & 11.84 & 6.41 & 0 \\
\hline 9296942 & Cyclin-T1 & CCNT1 & Cyclin & 12.87 & 0 & 0 \\
\hline 6226784 & Cyclin-dependent kinase 10 & CDK10 & CDK & 25.95 & 0 & 0 \\
\hline 205371737 & Anaphase-promoting complex subunit 4 & APC4 & Mitosis factor & 15.42 & 8.36 & 5.36 \\
\hline 37537861 & Anaphase-promoting complex subunit 5 & APC5 & Mitosis factor & 4.12 & 0 & 0 \\
\hline 37537762 & Cell division cycle protein 20 homolog & $\mathrm{CDC} 20$ & Mitosis factor & 12.48 & 0 & 0 \\
\hline 37537763 & Cell division cycle protein 16 homolog & $\mathrm{CDC} 16$ & Mitosis factor & 20.09 & 16.33 & 0 \\
\hline 254763423 & Cell division cycle protein 23 homolog & $\mathrm{CDC} 23$ & Mitosis factor & 15.65 & 0 & 7.26 \\
\hline 12644198 & Cell division cycle protein 27 homolog & $\mathrm{CDC} 27$ & Mitosis factor & 7.56 & 0 & 0 \\
\hline 12230256 & $\begin{array}{l}\text { Mitotic spindle assembly checkpoint } \\
\text { protein MAD2A }\end{array}$ & MD2L1 & Mitosis factor & 45.58 & 0 & 21.14 \\
\hline 729143 & Cyclin-dependent kinase inhibitor 1 & CDN1A & CDK inhibitor & 0 & 20.58 & 0 \\
\hline 3041660 & Cyclin-dependent kinase inhibitor 2A & CD2A1 & CDK inhibitor & 59.89 & 173.11 & 55.56 \\
\hline 172047302 & Cyclin-D1-binding protein 1 & CCNDBP1 & CDK inhibitor & 0 & 9.38 & 12.04 \\
\hline 1709658 & Serine/threonine-protein kinase PLK1 & PLK1 & Positive regulator & 30.99 & 5.60 & 0 \\
\hline 68571766 & DNA replication licensing factor MCM4 & MCM4 & Positive regulator & 21.65 & 7.82 & 15.06 \\
\hline 19858646 & DNA replication licensing factor MCM5 & MCM5 & Positive regulator & 67.89 & 59.79 & 59.04 \\
\hline 76803807 & Origin recognition complex subunit 1 & ORC1 & Positive regulator & 7.23 & 3.92 & 5.03 \\
\hline 6174924 & Origin recognition complex subunit 5 & ORC5 & Positive regulator & 21.48 & 7.76 & 19.92 \\
\hline 25091097 & $\begin{array}{l}\text { Double-strand-break repair protein } \\
\operatorname{rad} 21 \text { homolog }\end{array}$ & RAD21 & Positive regulator & 167.81 & 32.10 & 27.47 \\
\hline 13633914 & $\begin{array}{l}\text { Mothers against decapentaplegic } \\
\text { homolog } 2\end{array}$ & SMAD2 & Positive regulator & 13.34 & 7.23 & 9.28 \\
\hline 51338669 & $\begin{array}{l}\text { Mothers against decapentaplegic } \\
\text { homolog } 3\end{array}$ & SMAD3 & Positive regulator & 51.29 & 7.94 & 10.20 \\
\hline 29336622 & $\begin{array}{l}\text { Structural maintenance of } \\
\text { hromosomes protein } 1 \mathrm{~A}\end{array}$ & SMC1A & Positive regulator & 434.44 & 177.95 & 207.35 \\
\hline 29337005 & $\begin{array}{l}\text { Structural maintenance of } \\
\text { chromosomes protein } 3\end{array}$ & SMC3 & Positive regulator & 442.71 & 183.07 & 188.71 \\
\hline 209572720 & Cohesin subunit SA-1 & STAG1 & Positive regulator & 17.33 & 10.73 & 3.44 \\
\hline 73621291 & Cohesin subunit SA-2 & STAG2 & Positive regulator & 43.01 & 10.97 & 0 \\
\hline 135674 & Transforming growth factor $\beta-1$ & TGFB1 & Positive regulator & 23.96 & 0 & 0 \\
\hline 132164 & Retinoblastoma-associated protein & $\mathrm{RB}$ & Positive regulator & 3.36 & 0 & 0 \\
\hline 1345590 & 14-3-3 protein $\beta / \alpha$ & YWHAB & Negative regulator & 468.41 & 644.94 & 827.91 \\
\hline 51702210 & 14-3-3 protein $\varepsilon$ & YWHAE & Negative regulator & 708.35 & 1006.08 & 1053.59 \\
\hline 1345593 & 14-3-3 protein $\eta$ & YWHAH & Negative regulator & 215.22 & 343.05 & 563.68 \\
\hline 48428721 & 14-3-3 protein $\gamma$ & YWHAG & Negative regulator & 428.69 & 464.67 & 719.29 \\
\hline 112690 & $14-3-3$ protein $\theta$ & YWHAQ & Negative regulator & 483.03 & 771.58 & 937.41 \\
\hline 52000887 & $14-3-3$ protein $\zeta / \delta$ & YWHAZ & Negative regulator & 699.13 & 771.58 & 1025.84 \\
\hline 398953 & 14-3-3 protein $\sigma$ & SFN & Negative regulator & 452.08 & 476.40 & 698.92 \\
\hline
\end{tabular}


Table II. Continued.

Protein level (ppm)

Accession no.

Protein name

Symbol

Protein function

Untreated Romidepsin TSA

Regulation of apoptosis

Tumor necrosis factor receptor type 1-
associated DEATH domain protein

TRADD Pro-apoptosis

APAF Pro-apoptosis

20141188 Apoptotic protease-activating factor 1

18203316 Diablo homolog, mitochondrial

17376879 Serine protease HTRA2, mitochondrial

728945

Apoptosis regulator $\mathrm{BAX}$

DBLOH

Pro-apoptosis

2493274

Bcl-2 homologous antagonist/killer

2493285

BH3-interacting domain death agonist

23396740

Bcl-2-like protein 13

2810997

DNA fragmentation factor subunit $\alpha$

575773389 Serine-protein kinase ATM

77416852

Caspase-3

115612

Calpain small subunit 1

62906858 Interleukin-1 $\beta$

125987833 Interleukin-1 receptor-associated kinase-like 2

18202671 Myeloid differentiation primary response protein MyD88

21542418 Nuclear factor NF-kappa-B p105 subunit

125193 cAMP-dependent protein kinase type $\mathrm{I}-\alpha$ regulatory subunit

229463042 cAMP-dependent protein kinase type I- $\beta$ regulatory subunit

125198 cAMP-dependent protein kinase type II- $\alpha$ regulatory subunit

Regulation of DNA damage repair

73921676 DNA-(apurinic or apyrimidinic site) lyase 2

251757259 DNA ligase 3

317373290 DNA repair protein XRCC1

130781 Poly [ADP-ribose] polymerase 1

17380230 Poly [ADP-ribose] polymerase 2

296453081 DNA repair protein complementing XP-C cells

12643730 DNA damage-binding protein 1

12230033 DNA damage-binding protein 2

119541 TFIIH basal transcription factor complex helicase XPB subunit

17380326 General transcription factor IIH subunit 2

50403772 General transcription factor IIH subunit 3

17380328 General transcription factor IIH subunit 4

\section{HTRA2 Pro-apoptosis}

BAX Pro-apoptosis

BAK Pro-apoptosis

BID Pro-apoptosis

B2L13 Pro-apoptosis

DFFA Pro-apoptosis

ATM Pro-apoptosis

CASP3 Caspase

CPNS1 Calpain-calcium

IL1B Pro-survival

IRAK2 Pro-survival

MYD88 Pro-survival

NFKB1 Pro-survival

PRKAR1A Pro-survival

PRKAR1B Pro-survival

PRKAR2A Pro-survival

APEX2 Base excision repair

LIG3

XRCC1

Base excision repair

PARP1

Base excision repair

PARP2

XPC

Base excision repair

Nucleotide

excision repair

DDB1

Nucleotide excision repair

DDB2

Nucleotide excision repair

ERCC3 Nucleotide excision repair

GTF2H2

Nucleotide excision repair

GTF2H3

Nucleotide excision repair

GTF2H4 Nucleotide excision repair
0

12.02

37.04

49.20

380.84

26.71

3.31

10.82

0

0

195.46

5.41

253.83

54.40

211.86

75.69

97.32

73.70

203.12

63.99

41.07

31.94

207.73

88.89

12.84

20.88

26.80

40.79

39.27

1.02

1.10

2.84

24.37

46.93

151.15

129.35

46.31

0

16.11

0

0

10.52

0

0

9.65

0

0

147.13

8.86

34.12

32.70

0

0

75.20

85.81

188.50

109.56

148.24

29.17

0

10.15

31.86

17.27

11.08

31.54

8.55

0

30.33

21.92

14.07

74.15

7.31

56.28 
Table II. Continued.

Accession no.

Protein level (ppm)

\begin{tabular}{|c|c|c|c|c|c|c|}
\hline & Protein name & Symbol & Protein function & Untreated & Romidepsin & TSA \\
\hline 1706232 & Cyclin-H & $\mathrm{CCNH}$ & $\begin{array}{l}\text { Nucleotide } \\
\text { excision repair }\end{array}$ & 28.93 & 10.45 & 26.83 \\
\hline 25091548 & Pre-mRNA-splicing factor SYF1 & XAB2 & $\begin{array}{l}\text { Nucleotide } \\
\text { excision repair }\end{array}$ & 87.42 & 51.33 & 35.48 \\
\hline 108936013 & Cullin-4A & CUL4A & $\begin{array}{l}\text { Nucleotide } \\
\text { excision repair }\end{array}$ & 36.93 & 22.24 & 22.84 \\
\hline 60392986 & DNA repair protein RAD50 & RAD50 & $\begin{array}{l}\text { Homologous } \\
\text { recombination }\end{array}$ & 71.21 & 51.46 & 36.33 \\
\hline 17380137 & $\begin{array}{l}\text { Double-strand break repair } \\
\text { protein MRE11A }\end{array}$ & MRE11A & $\begin{array}{l}\text { Homologous } \\
\text { recombination }\end{array}$ & 39.59 & 4.77 & 24.48 \\
\hline 74762960 & Nibrin & NBN & $\begin{array}{l}\text { Homologous } \\
\text { recombination }\end{array}$ & 41.30 & 13.4 & 5.75 \\
\hline 116242745 & DNA endonuclease RBBP8 & RBBP8 & $\begin{array}{l}\text { Homologous } \\
\text { recombination }\end{array}$ & 3.47 & 0 & 0 \\
\hline 166898077 & $\begin{array}{l}\text { Crossover junction endonuclease } \\
\text { MUS81 }\end{array}$ & MUS81 & $\begin{array}{l}\text { Homologous } \\
\text { recombination }\end{array}$ & 5.65 & 0 & 0 \\
\hline 2501242 & DNA topoisomerase $3-\alpha$ & TOP3A & $\begin{array}{l}\text { Homologous } \\
\text { recombination }\end{array}$ & 3.11 & 0 & 0 \\
\hline 38258929 & $\begin{array}{l}\text { DNA-dependent protein kinase } \\
\text { catalytic subunit }\end{array}$ & PRKDC & $\begin{array}{l}\text { Non-homologous } \\
\text { end-joining }\end{array}$ & 521.31 & 295.21 & 363.21 \\
\hline 125731 & $\begin{array}{l}\text { X-ray repair cross-complementing } \\
\text { protein } 5\end{array}$ & XRCC5 & $\begin{array}{l}\text { Non-homologous } \\
\text { end-joining }\end{array}$ & 582.87 & 387.37 & 443.99 \\
\hline 125729 & $\begin{array}{l}\text { X-ray repair cross-complementing } \\
\text { protein } 6\end{array}$ & XRCC6 & $\begin{array}{l}\text { Non-homologous } \\
\text { end-joining }\end{array}$ & 772.18 & 454.52 & 619.04 \\
\hline 74760390 & WD repeat-containing protein 48 & WDR48 & Fanconi anemia & 4.60 & 0 & 0 \\
\hline 48428038 & Aprataxin & APTX & $\begin{array}{l}\text { Editing and } \\
\text { processing nuclease }\end{array}$ & 43.74 & 0 & 0 \\
\hline 146325723 & E3 ubiquitin-protein ligase SHPRH & SHPRH & $\begin{array}{l}\text { Ubiquitination } \\
\text { and modification }\end{array}$ & 1.85 & 0 & 0 \\
\hline 68565701 & Telomere-associated protein RIF1 & RIF1 & Other related & 51.65 & 15.02 & 8.76 \\
\hline 1705919 & Dual specificity protein kinase CLK2 & CLK2 & Other related & 12.48 & 0 & 0 \\
\hline 55976619 & Pre-mRNA-processing factor 19 & PRPF19 & Other related & 463.44 & 241.12 & 335.32 \\
\hline \multicolumn{7}{|c|}{ ROS generation } \\
\hline 14916998 & Glutathione reductase & GSHR & Reductase & 17.90 & 6.47 & 8.30 \\
\hline 182705230 & Thioredoxin reductase 2 & TRXR2 & Reductase & 17.83 & 0 & 0 \\
\hline 2506326 & Xanthine dehydrogenase/oxidase & $\mathrm{XDH}$ & Oxidase & 0 & 2.67 & 2.53 \\
\hline \multicolumn{7}{|c|}{ Regulation of autophagy } \\
\hline 254763436 & $\begin{array}{l}\text { Protein kinase, AMP- } \\
\text { activated, } \alpha 1 \text { catalytic subunit }\end{array}$ & PRKAA1 & Autophagy & 22.28 & 36.23 & 46.51 \\
\hline 20178289 & Interferon, $\alpha 21$ & IFNA21 & Autophagy & 0 & 17.86 & 0 \\
\hline 74762700 & $\begin{array}{l}\text { Phosphoinositide-3-kinase, } \\
\text { regulatory subunit } 4\end{array}$ & PIK3R4 & Autophagy & 0 & 4.97 & 3.19 \\
\hline 74730233 & $\begin{array}{l}\text { Phosphatidylinositol 3-kinase, } \\
\text { catalytic subunit type } 3\end{array}$ & PIK3C3 & Autophagy & 0 & 3.81 & 4.89 \\
\hline 62286592 & Autophagy related 7 & ATG & Autophagy & 22.15 & 62.42 & 12.33 \\
\hline 62510482 & $\begin{array}{l}\text { Autophagy related 16-like } 1 \\
(\text { S. cerevisiae })\end{array}$ & ATG16L1 & Autophagy & 5.13 & 11.12 & 0 \\
\hline 44888808 & $\begin{array}{l}\mathrm{GABA}(\mathrm{A}) \text { receptor- } \\
\text { associated protein-like } 2\end{array}$ & GABARAPL & Autophagy & 0 & 28.85 & 111.11 \\
\hline 61212142 & Autophagy related 3 & ATG3 & Autophagy & 0 & 10.75 & 55.20 \\
\hline
\end{tabular}

ROS, reactive oxygen species. 

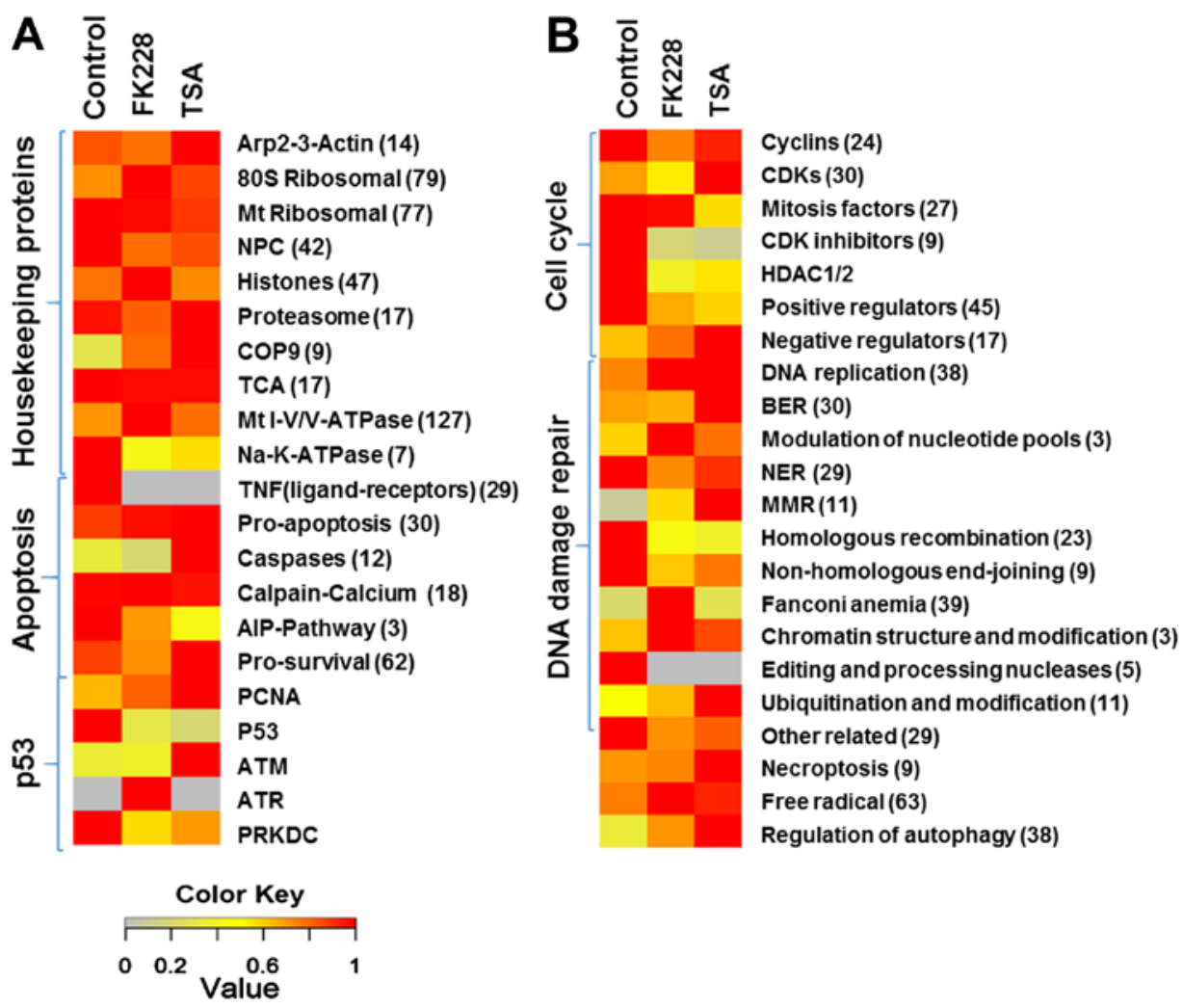

Figure 3. Protein expression profile of the bladder cancer 5637 cells treated with romidepsin (FK228) and trichostatin A (TSA). Heat map showing clustering analysis of the proteins with altered expression based on cellular pathways in FK228 or TSA treated 5637 cells compared to those of the untreated control cells. Proteins were annotated based on the Kyoto Encyclopedia of Genes and Genomes pathway database. (A) Heat map showing the identified and quantified housekeeping proteins and the proteins in p53 and apoptosis pathways. (B) Heat map showing the identified and quantified proteins in DNA damage repair, cell cycle regulation, necroptosis, free radical generation and autophagy pathways. The numbers of the identified and quantified proteins in each category are shown in parentheses. The indicated color scale is based on relative quantifications (ppm) assigning the highest ppm as 1 . Gray, signal was not detected.

Table III. Histone deacetylase inhibitors induce enhanced global lysine acetylation in histones and non-histone proteins in 5637 bladder cancer cells as determined by proteomic analysis.

\begin{tabular}{lcc}
\hline Treatment & Histone protein & Non-histone protein \\
\hline Untreated & 172 & 426 \\
Romidepsin & 422 & 841 \\
Trichostatin A & 280 & 638 \\
\hline
\end{tabular}

For example, our data showed that multiple autophagyassociated proteins, such as ATG3, PRKAA1, GABARAPL and ATG7, were highly upregulated (Table II), suggesting that these proteins might have important roles in HDACI-induced autophagy in bladder carcinoma.

HDACIs enhance global histone and non-histone protein acetylation levels and induce deregulation of chromatin modification proteins. Since both romidepsin and TSA are HDACIs, we assessed the effect of the two HDACIs on lysine acetylation in 5637 cells. We first verified whether inhibition of histone deacetylation by the HDACIs altered global acetylation in our model system. We searched the whole cell proteome and identified the non-redundant peptides containing the acetylated lysine residues. As shown in Table III, both romidepsin and TSA significantly increased global histone and non-histone lysine acetylation levels compared to the untreated control. Romidepsin induced $\sim 2.5$ fold and 2-fold increases in histone and non-histone protein acetylation levels, respectively $(\mathrm{P}<0.01)$, while TSA increased global lysine acetylation levels 63 and 50\% in histone and non-histone proteins, respectively $(\mathrm{P}<0.05)$, indicating that romidepsin exerts a more potent effect than TSA on the lysine acetylated profile of both non-histone substrates and core histones in 5637 cells.

Next, the overall increased lysine acetylation levels in histone proteins prompted us to further investigate the impact of HDACIs on site-specific histone lysine acetylation. To this end, we applied the quantitative proteomics to profile histone lysine acetylation in 5637 cells after romidepsin or TSA treatment, followed by protein sequence database search for peptide identification and post-translational modification site mapping. The diagram of Fig. 4 shows that a total of 23 lysine acetylation (Kac) sites in core histones were identified, in most of them Kac sites were previously reported in core histones in mammalian cells. Importantly, we identified two new histone marks, including H2AK118ac and H2BK34ac in both romidepsin and TSA treated 5637 cells (Fig. 4A and B). The representative spectra of histone lysine acetylated peptides are shown in Fig. $4 \mathrm{C}$ and D, including the spectra for peptides of H2AK118ac and H2BK34ac. In addition, the sequences of 
A H2A: $\mathrm{NH}_{2}$-SGRGKQGGK...RAGLQFPVGRVHRLL...QAVLLPKKTESH...AKGK-COOH 118119

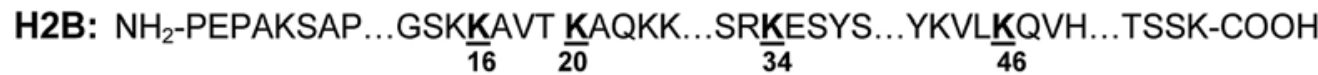

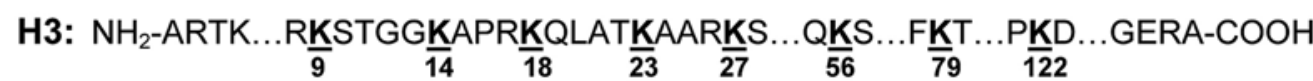

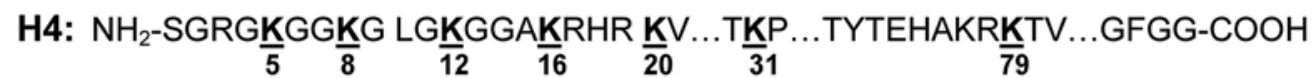

B H2A: $\mathrm{NH}_{2}$-SGRGKQGGK...RAGLQFPVGRVHRLL...QAVLLPKKTESH...AKGK-COOH 118119

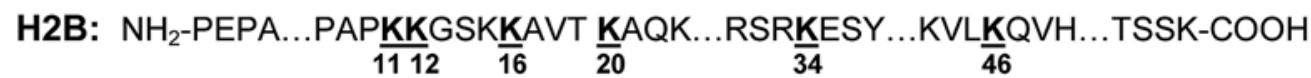

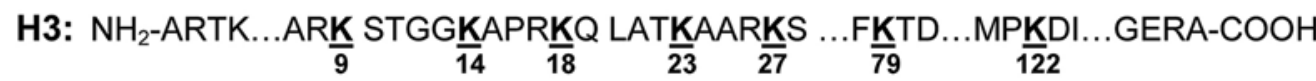

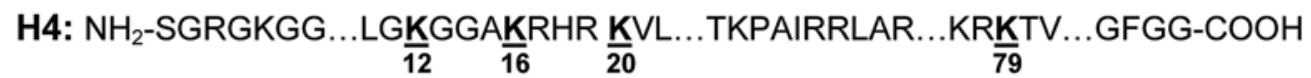

C

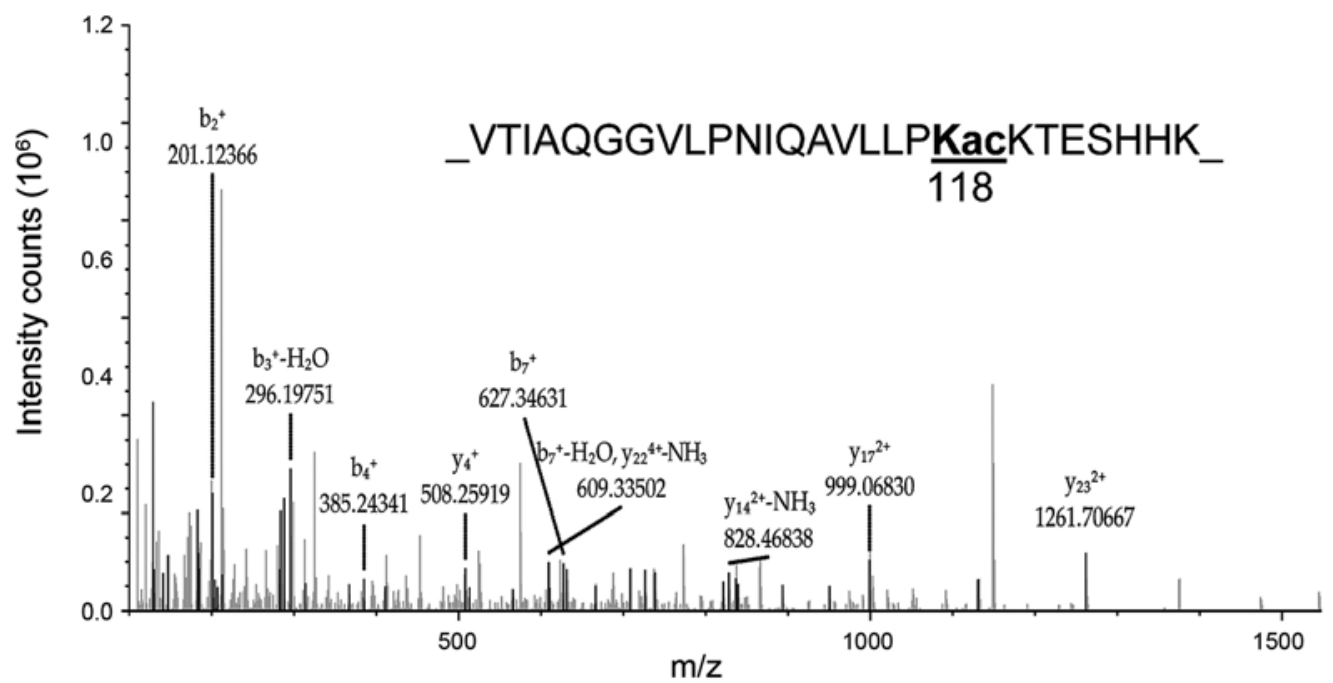

D

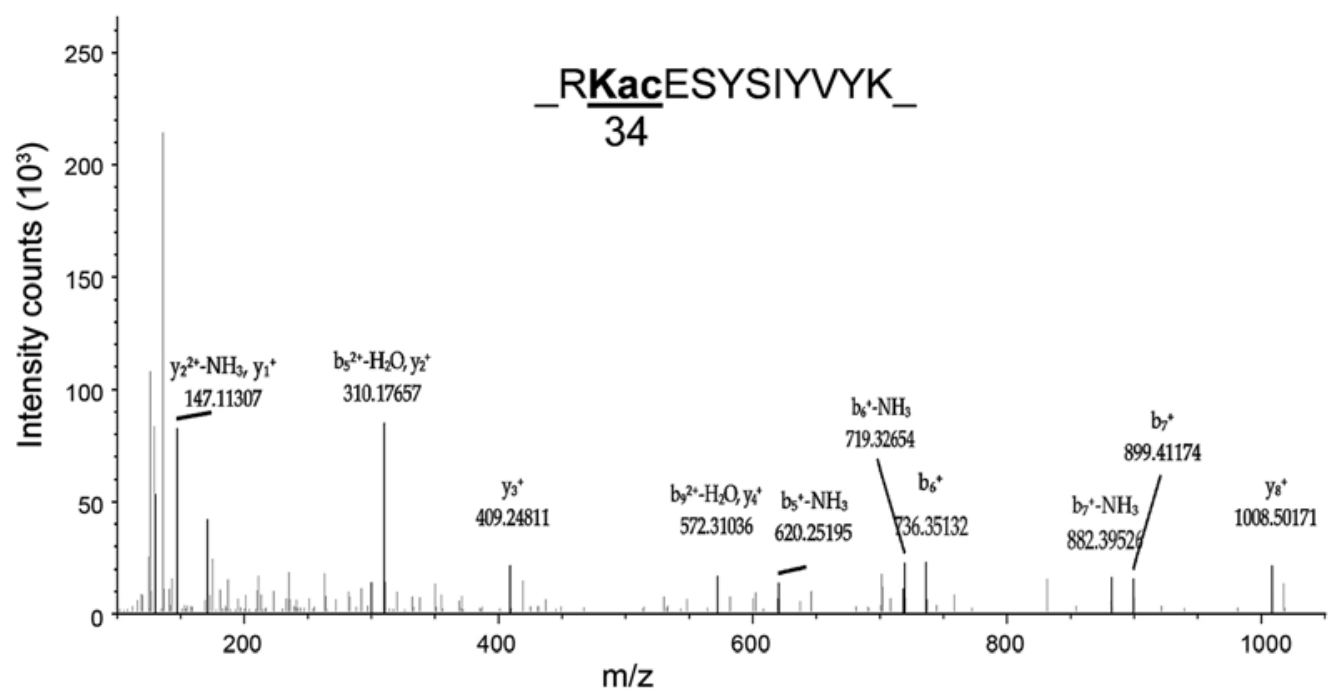

Figure 4. Identification and quantitation of lysine acetylation in core histones of the 5637 bladder cancer cells. The illustration of identified lysine acetylation sites in core histones in the 5637 cells in response to romidepsin (A) and trichostatin A (B) exposure. The identified acetylation sites in core histones are numbered and underlined. (C) MS/MS spectra of a tryptic peptide histone H2AK118 acetylated peptide _VTIAQGGVLPNIQAVLLPK(ac)K(ac)TESHHK_ and (D) MS/MS spectra of a tryptic peptide histone H2BK34 acetylated peptide _ RK(ac)ESYSIYVYK_. 
Table IV. The identified lysine acetylation (Kac) sites in core histones and the lysine-acetylated peptide sequences in histone deacetylase inhibitor-treated bladder cancer 5637 cells.

\begin{tabular}{|c|c|}
\hline Modified histone site & Modified peptide sequence \\
\hline \multicolumn{2}{|l|}{ Romidepsin treatment } \\
\hline $\mathrm{H} 2 \mathrm{AK} 118 \mathrm{ac}$ & _VTIAQGGVLPNIQAVLLPK(ac)K(ac)TESHHK_ \\
\hline H2AK119ac & _VTIAQGGVLPNIQAVLLPK $(\mathrm{ac}) \mathrm{K}(\mathrm{ac})_{-}$ \\
\hline H2BK16ac & _K(ac)AVTK(ac)AQK_ \\
\hline H2BK20ac & _K(ac)AVTK(ac)AQK_ \\
\hline H2BK34ac & _K(ac)ESYSIYVYK_ \\
\hline $\mathrm{H} 2 \mathrm{BK} 46 \mathrm{ac}$ & _VLK(ac)QVHPDTGISSK_ \\
\hline H3K9ac & _K(ac)STGGK(ac)APR_ \\
\hline $\mathrm{H} 3 \mathrm{~K} 14 \mathrm{ac}$ & _K(ac)STGGK(ac)APR_ \\
\hline $\mathrm{H} 3 \mathrm{~K} 18 \mathrm{ac}$ & $\_\mathrm{K}(\mathrm{ac}) \mathrm{QLATK}(\mathrm{ac}) \mathrm{AAR} \_$ \\
\hline $\mathrm{H} 3 \mathrm{~K} 23 \mathrm{ac}$ & _K(ac)QLATK(ac)AAR_ \\
\hline $\mathrm{H} 3 \mathrm{~K} 27 \mathrm{ac}$ & _K(ac)SAPATGGVKKPHR_ \\
\hline $\mathrm{H} 3 \mathrm{~K} 56 \mathrm{ac}$ & _YQK(ac)STELLIR_ \\
\hline $\mathrm{H} 3 \mathrm{~K} 79 \mathrm{ac}$ & _EIAQDFK(ac)TDLR_ \\
\hline $\mathrm{H} 3 \mathrm{~K} 122 \mathrm{ac}$ & _VTIMPK(ac)DIQLAR_ \\
\hline H4K5ac & _GK(ac)GGK(ac)GLGK_ \\
\hline $\mathrm{H} 4 \mathrm{~K} 8 \mathrm{ac}$ & _GK(ac)GGK(ac)GLGK_ \\
\hline $\mathrm{H} 4 \mathrm{~K} 12 \mathrm{ac}$ & _GLGK(ac)GGAK(ac)R_ \\
\hline $\mathrm{H} 4 \mathrm{~K} 16 \mathrm{ac}$ & _GLGK(ac)GGAK(ac)R_ \\
\hline H4K20ac & _K(ac)VLRDNIQGITKPAIR_ \\
\hline $\mathrm{H} 4 \mathrm{~K} 31 \mathrm{ac}$ & _DNIQGITK(ac)PAIR_ \\
\hline $\mathrm{H} 4 \mathrm{~K} 79 \mathrm{ac}$ & _K(ac)TVTAMDVVYALKR_ \\
\hline \multicolumn{2}{|l|}{ Trichostatin A treatment } \\
\hline H2AK118ac & _VTIAQGGVLPNIQAVLLPK(ac)K(ac)TESHHK_ \\
\hline H2AK119ac & _VTIAQGGVLPNIQAVLLPK(ac)K(ac)_ \\
\hline H2BK11ac & _SAPAPK(ac)K(ac)GSK_ \\
\hline $\mathrm{H} 2 \mathrm{BK} 12 \mathrm{ac}$ & _SAPAPK(ac)K(ac)GSK_ \\
\hline H2BK16ac & _K(ac)AVTK(ac)AQK_ \\
\hline H2BK20ac & _K(ac)AVTK(ac)AQK_ \\
\hline $\mathrm{H} 2 \mathrm{BK} 34 \mathrm{ac}$ & _K(ac)ESYSIYVYK_ \\
\hline H2BK46ac & _VLK(ac)QVHPDTGISSK_ \\
\hline $\mathrm{H} 3 \mathrm{~K} 9 \mathrm{ac}$ & KK(ac)STGGK(ac)APR_ \\
\hline $\mathrm{H} 3 \mathrm{~K} 14 \mathrm{ac}$ & _K(ac)STGGK(ac)APR_ \\
\hline $\mathrm{H} 3 \mathrm{~K} 18 \mathrm{ac}$ & _K(ac)QLATK(ac)AAR_ \\
\hline $\mathrm{H} 3 \mathrm{~K} 23 \mathrm{ac}$ & _K(ac)QLATK(ac)AAR_ \\
\hline $\mathrm{H} 3 \mathrm{~K} 27 \mathrm{ac}$ & _K(ac)SAPATGGVKKPHR_ \\
\hline $\mathrm{H} 3 \mathrm{~K} 79 \mathrm{ac}$ & _EIAQDFK(ac)TDLR_ \\
\hline $\mathrm{H} 3 \mathrm{~K} 122 \mathrm{ac}$ & _VTIMPK(ac)DIQLAR_ \\
\hline $\mathrm{H} 4 \mathrm{~K} 12 \mathrm{ac}$ & _GLGK(ac)GGAK(ac)R_ \\
\hline $\mathrm{H} 4 \mathrm{~K} 16 \mathrm{ac}$ & _GLGK(ac)GGAK(ac)R_ \\
\hline $\mathrm{H} 4 \mathrm{~K} 20 \mathrm{ac}$ & _K(ac)VLRDNIQGITKPAIR_ \\
\hline $\mathrm{H} 4 \mathrm{~K} 79 \mathrm{ac}$ & _K(ac)TVTAMDVVYALKR_ \\
\hline
\end{tabular}

the identified lysine acetylated peptides in core histones in romidepsin and TSA treated cells are listed in Table IV.

Finally, we quantified dynamic change in global protein abundance of the chromatin modifying proteins in HDACIinduced bladder cancer cells. Unexpectedly, we found that the protein levels of HDAC1, HDAC2 and HDAC3 in the deacety- lation complexes of Mi-2/NuRD, CoREST, NcoR, SMRT and Sin3 were all downregulated in both romidepsin and TSA treated cells. As seen in Table V, treatment with romidepsin and TSA induced 2- and 1.7-fold downregulation for HDAC1, 3.2- and 2-fold downregulation for HDAC2, and 5.5- and 2.2-fold downregulation for HDAC3, respectively. The levels 
Table V. The differentially expressed chromatin modifying proteins in response to histone deacetylase inhibitor treatment in bladder cancer 5637 cells.

Protein level (ppm)

Accession no.

\begin{tabular}{|c|c|c|c|c|c|c|c|}
\hline \multirow{2}{*}{ 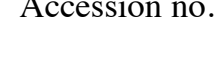 } & \multirow[b]{2}{*}{ Protein name } & \multirow[b]{2}{*}{ Symbol } & \multirow{2}{*}{ Complex } & \multirow[b]{2}{*}{ Protein function } & \\
\hline & & & & & Untreated & Romidepsin & TSA \\
\hline 2498443 & Histone deacetylase 1 & HDAC1 & $\begin{array}{l}\text { Mi-2/NuRD; } \\
\text { CoREST; Sin } 3\end{array}$ & Lysine deacetylase & 374.75 & 189.09 & 224.75 \\
\hline 68068066 & Histone deacetylase 2 & HDAC2 & $\begin{array}{l}\text { Mi-2/NuRD; } \\
\text { CoREST; Sin } 3\end{array}$ & Lysine deacetylase & 421.20 & 131.42 & 213.11 \\
\hline 3334210 & Histone deacetylase 3 & HDAC3 & $\begin{array}{l}\text { Mi-2/NuRD; } \\
\text { NcoR/SMRT }\end{array}$ & Lysine deacetylase & 87.32 & 15.77 & 40.49 \\
\hline 74717977 & $\begin{array}{l}\text { Histone deacetylase } \\
\text { complex subunit } \\
\text { SAP130 }\end{array}$ & SP130 & $\operatorname{Sin} 3$ & Repressor & 17.83 & 6.44 & 8.26 \\
\hline 68053233 & $\begin{array}{l}\text { Sin3 histone deacetylase } \\
\text { corepressor complex } \\
\text { component SDS3 }\end{array}$ & SDS3 & $\operatorname{Sin} 3$ & Corepressor & 37.98 & 0 & 26.42 \\
\hline 3334209 & $\begin{array}{l}\text { Histone acetyltransferase } \\
\text { type B catalytic subunit }\end{array}$ & HAT1 & KATs & Lysine acetyltransferase & 52.02 & 48.34 & 103.42 \\
\hline 215274095 & $\begin{array}{l}\text { Histone acetyltransferase } \\
\text { KAT6A }\end{array}$ & KAT6A & KATs & Lysine acetyltransferase & 1.55 & 3.37 & 2.16 \\
\hline
\end{tabular}

TSA, trichostatin A.

of Sin3 histone deacetylase corepressor complex component SDS3, a regulatory protein that augments histone deacetylase activity of HDAC1, were also reduced in response to exposure to romidepsin or TSA (Table V). Additionally, romidepsin and TSA decreased the levels of histone deacetylase complex subunit SAP130 by 2.8- and 2.2-fold, respectively, in the 5637 cells. In contrast, the levels of the lysine acetyltransferase KAT6A and histone acetyltransferase type B catalytic subunit, the latter acetylates histone $\mathrm{H} 4$ at H4K5ac and H4K12ac, were both elevated following the HDACI induction (Table V). These data suggest that romidepsin and TSA induced global acetylation in core histones and non-histone proteins are mediated partly through the elevated levels of HATs and reduced levels of HDACs in 5637 bladder cancer cells.

\section{Discussion}

Although HDACIs such as romidepsin and vorinostat (SAHA) have been approved for the treatment of CTCL, there is no currently approved HDACI for any solid tumor indication; therefore, we explored the potential for the development of HDACI as a novel therapeutic for bladder urothelial carcinoma. In the present study, we have demonstrated that romidepsin, SAHA and TSA suppressed cell growth and caused cell death in 5637 bladder cancer cells in vitro. Furthermore, our quantitative proteomic studies showed that 2472 proteins were 2 -fold upregulated and 2049 proteins were 2 -fold downregulated in this model in response to romidepsin and TSA exposure, among them $1082 \geq 2$-fold upregulated proteins and $1140 \geq 2$-fold downregulated proteins were common to both romidepsin and TSA treatment, as compared to the untreated controls $(\mathrm{P}<0.05)$. The subsequent bioinformatic analysis revealed that those differentially expressed proteins were mainly involved in biological and metabolic functions and cell death associated pathways. HDACI exposure also enhanced global acetylation levels in both histone and non-histone proteins. Twenty-three lysine acetylation marks were detected on core histones in HDACI-treated bladder cancer cells including two newly identified histone Kac sites (H2AK118ac and H2BK34ac). These data suggest that HDACI-induced alterations in protein expression is mediated, at least in part, through histone modification, leading to changes in biological and metabolic functions and cell death in bladder cancer cells. By establishing the link between histone modification and whole proteome in response to HDACI treatment, this study may deepen our understanding of HDACI-mediated therapeutics in bladder cancer.

A major goal of the chemotherapy of human malignancies is the inhibition of cell proliferation, and drug-induced cancer cell growth arrest is mediated partly by blocking cell cycle progression (23). The eukaryotic cell cycle is regulated via the sequential activation and inactivation of cyclin-dependent kinases (CDKs) that drive cell cycle progression through the phosphorylation and dephosphorylation of regulatory proteins (24-26). The activities of CDKs are positively regulated by cyclins and negatively regulated by CDK inhibitors (CKIs). Thus, the cell cycle is regulated by cyclins, CDKs and CKIs. Changes in the expression of specific CDKs or their regulatory proteins such as cyclins and CKIs can lead to uncontrolled cell proliferation and eventually to carcinogenesis $(25,27)$. Whereas, downregulating the levels of cyclins or upregulating CKIs lead to blockade of cell cycle progression.

In this study, we showed that romidepsin and TSA downregulated the protein expression of cyclins B1/B2 and upregulated the expression of anaphase promoting complex-1 
(APC1) and 14-3-3 proteins in 5637 cells. Cyclin B binds to and activates CDK1. The complex of cyclin $\mathrm{B}$ and CDK1 is responsible for the control of G2/M checkpoint, while APC1 acts by mediating ubiquitination and degradation of cyclin $\mathrm{B}$ and subsequent inactivation of CDK1. On the other hand, CDK1 activity is suppressed via phosphorylation of Thr-14 and Tyr-15 by the Wee-1 protein kinase (28) and is activated by $\mathrm{CDC} 25$ protein phosphatases, which function to remove the inhibitory phosphates from CDK1 (29). 14-3-3 proteins are involved in the regulation of G2/M checkpoint by 14-3-3-mediated CDC25 inactivation and Wee-1 activation. Romidepsin and TSA caused reduced levels of cyclin B and elevated levels of APC1 and 14-3-3 proteins in 5637 cells, suggesting that romidepsin and TSA suppress bladder cancer cell proliferation through cell cycle blockade at the G2/M phase, and that this occurs via the HDACI downregulation of cyclin B and upregulation of APC1 and 14-3-3 proteins, leading to cell cycle arrest and cell growth suppression in bladder cancer cells.

The other goal of cancer chemotherapy is to commit tumor cells to death or apoptosis following exposure to anticancer agents. Apoptosis is a highly regulated cellular process between cell proliferation and cell death and drug-induced cell death is mediated, at least in part, by apoptotic cell death (30).

In the present study, we found that the levels of caspase-3 were significantly increased in 5637 cells following treatment with romidepsin or TSA. In addition, both romidepsin and TSA enhanced Bax and Bak expression and triggered phosphorylation of Bcl-2 at Ser-70. It is known that the expression of pro-apoptotic proteins is mediated through p53-dependent and -independent pathways. In this study, we showed that the levels of p53 protein as well as other p53-pathway proteins, such as DNA-dependent protein kinase (PRKDC), were not elevated in response to HDACI exposure (Fig. 3A), and we confirmed by DNA sequencing that p53 gene is mutated in this cell line (data not shown), suggesting that the increased expression of apoptosis-associated proteins is not under direct control by p53 in 5637 bladder carcinoma cells. Additionally, it has been shown that phosphorylation of Bcl-2 is induced by several drugs in a panel of cancer cell lines derived from leukemia, lymphoma, and breast and prostate cancer (31-35). Phosphorylation of $\mathrm{Bcl}-2$ is cell cycle-dependent, occurs at G2/M (34) and results in concomitant apoptosis $(34,36)$. Interestingly, treatment with HDACIs was found to induce Bcl-2 Ser-70 phosphorylation at the G2/M phase of the cell cycle, with concomitant apoptosis in bladder cancer cells. This is consistent with the literature reporting that $\mathrm{Bcl}-2$ phosphorylation at Ser-70 and loss of anti-apoptotic function in response to antitumor drugs and subsequent elimination of tumor cells via apoptosis (35). These results suggest that a similar mechanism (Bcl-2 phosphorylation at $\mathrm{G} 2 / \mathrm{M}$ ) may be involved with induction of apoptosis by HDACIs in this model system. Taken together, these data strongly support the involvement of Bcl-2 family proteins in HDACI-induced apoptosis, possibly acting through a p53-independent, mitochondria-dependent intrinsic apoptotic pathway in human bladder cancer 5637 cells.

A wide range of DNA damage can be inflicted, both from extracellular agents including some antitumor drugs and via endogenous mechanisms (37). Genotoxic cancer therapeutics such as cisplatin and mitomycin C bind to DNA, forming adducts that in turn can be repaired by the DNA repair machinery or lead to permanent DNA damage. Anticancer agent-induced DNA damage leads to transient arrest in the G1, S, G2 and M phases of the cell cycle, allowing cells to have sufficient time to repair damaged DNA before resuming cell cycle progression. However, severe DNA injury that is too extensive for intracellular repair mechanisms will lead to activation of intrinsic apoptosis pathway and cell death. Although DNA damage also affects normal cells, tumor cells are often more vulnerable because of defects in DNA repair pathways or critical cell cycle checkpoints.

Five main mechanisms are involved in DNA repair: i) base excision repair, which corrects non-bulky damage; ii) nucleotide excision repair, which corrects lesions that disrupt the double helical structure of DNA; iii) mismatch repair, which corrects replication errors; iv) double-strand break repair, which corrects double-strand breaks through two different pathways, homologous recombination and nonhomologous end-joining; and v) direct repair, which corrects methylated or alkylated bases (38). Although the DNA lesions induced directly by HDACIs or indirectly via endogenous mechanisms such as the generation of free radicals, as well as the relevant DNA repair mechanisms responsible for the removal of those lesions in 5637 cells are still not known, our proteomic analysis revealed that the levels of multiple DNA repair proteins in multiple repair mechanisms were decreased in HDACI-treated bladder cancer cells. For example, the protein expression of XRCC 1 and PARP1/2 in base excision repair, XPC and ERCC3 in nucleotide excision repair, RAD50 and MRE11A in homologous recombination, and XRCC5 and XRCC6 in non-homologous end-joining were all reduced after romidepsin and TSA treatment. The downregulation of DNA repair protein expression by HDACIs significantly impairs cellular DNA repair activity and DNA damage response, which in turn results in inhibition of transcription, replication, and chromosome segregation leading to blockade of cell cycle progression or apoptosis in bladder carcinoma cells.

Studies suggest oxidative stress as a mechanism to the primary modes of action of antitumor agents. Oxidative stress is a redox (reduction-oxidation) disequilibrium state, in which the generation of ROS overwhelms the antioxidant defense mechanisms (39). ROS such as superoxide and hydroxyl radicals are highly toxic, as a result of their actions as oxidizing agents and can have damaging effects on cell physiology. Under conditions that can cause oxidative stress, cells are exposed to excessive ROS that can oxidize membrane fatty acids, initiating lipid peroxidation, oxidize proteins (40) and cause DNA damage (41). At high level, excessive ROS may cause severe damage to cells, including necrosis and apoptosis (42).

Redox state in the cell is regulated by redox proteins. In this study, we found that romidepsin and TSA downregulated the expression of glutathione reductase (GSHR) and thioredoxin reductase 2 (TRXR2) and upregulated the expression of xanthine dehydrogenase/oxidase (XDH), which lead to ROS formation in 5637 cells. These findings suggest that oxidative stress is involved in the antitumor effects of HDACIs in bladder cancer and that exposure to HDACIs may alter the antioxidant defense system and redox mechanisms in cells. This notion is supported by the reports from other researchers demonstrating that HDACIs induce cell death through ROS production (43). 


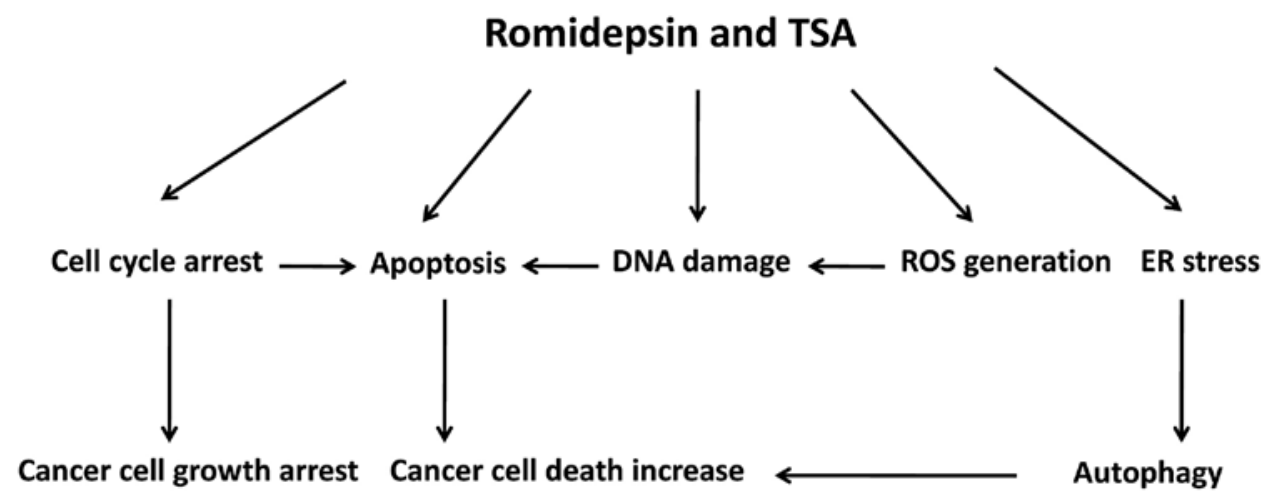

Figure 5. Potential pathways involved in the induction of cell cycle arrest and apoptotic cell death by romidepsin and trichostatin A (TSA) in bladder cancer. Proteomic analysis identified 97 differentially expressed proteins that were commonly regulated by both romidepsin and TSA when compared to untreated control cells (Table II). These proteins are involved in cell cycle progression, apoptosis process, DNA damage repair, oxidative stress and autophagy regulation. See the text for details. ER, endoplasmic reticulum; ROS, reactive oxygen species.

Although the mechanism for the link between HDACIinduced oxidative stress and cell death is not well understood, several lines of evidence suggest that HDACIs induce cell death via ROS generation by the following mechanisms: i) excess of ROS may facilitate the detachment of cytochrome $c$ from the mitochondrial membrane and increases the mobilized pool of cytochrome $c$, which is a prerequisite for its release into the cytoplasm through the pores created by pro-apoptotic Bcl-2 family members such as Bax and Bak; ii) ROS may also directly damage mitochondrial membrane and induce membrane potential loss that favors cytochrome $c$ release; iii) death receptor aggregation may also result from ROS production and induce cell death through a different pathway; iv) downregulation of anti-apoptotic molecules and/or upregulation of pro-apoptotic signals are involved in ROS-induced cell death (44); and v) HDACI-induced ROS causes oxidative DNA damage (43), as evidenced by the levels of phosphorylated histone $\mathrm{H} 2 \mathrm{AX}(\gamma-\mathrm{H} 2 \mathrm{AX})$ and ataxia telangiectasia mutated (ATM), early markers of DNA damage, significantly increase after the administration of HDACIs $(45,46)$. Cellular oxidative DNA damage induced by endogenous ROS production via HDACI treatment can lead to bladder cancer cell death (47).

Combining our results discussed above, we propose a possible mechanism by which HDACIs cause bladder cancer cell growth arrest and cell death as shown in Fig. 5. In this model, HDACIs alter changes in the levels and activities of proteins involved in the signaling pathways of cell cycle progression, apoptotic cell death, DNA damage repair, ROS generation, endoplasmic reticulum (ER) stress (48-50) and autophagy regulation (51), which are associated with cell death. In the proposed pathways depicted here (Fig. 5), romidepsin and TSA induce cell cycle arrest and apoptotic cancer cell death; cell cycle blockade not only causes cancer cell growth arrest, but prolonged cell cycle arrest also triggers cell suicide, usually in the form of apoptosis. In addition, the HDACIs increase DNA damage directly or indirectly through ROS production, which in turn promotes apoptosis. On the other hand, romidepsin and TSA mediate cancer cell death via inducing ER stress and autophagy. Because HDACIs target cell survival and cell death through multiple closely related but distinct mechanisms, they may act collaboratively or synergistically to promote apoptotic death of bladder cancer cells through these signaling pathways and their downstream molecular events.

Finally, our data indicate that dysregulation of protein expression in HDACI-treated 5637 cells was associated with enhanced lysine acetylation in histone and non-histone proteins as well as alterations in the levels of chromatin modifying proteins, suggesting a role for epigenetic modification.

The three main epigenetic mechanisms (DNA methyltion, histone modifications and RNA-mediated gene silencing) have been studied primarily in the context of gene expression $(52,53)$. The second epigenetic mechanism encompasses various histone modifications, including acetylation, glycosylation, methylation, phosphorylation and ubiquitination of specific residues in the N-terminal tails of histones (54). Histone modifications are post-translational alterations of histone proteins that interact with DNA to form a complex known as chromatin (54). Besides regulating several cellular processes including gene transcription, proliferation, and autophagy, histone modifications also affect many other chromatin-based processes such as DNA repair, replication and recombination (54).

The best-studied histone modification is lysine acetylation. The acetylation of histone modulates transcription by altering the accessibility of DNA to proteins, such as transcriptional regulators (transcriptional activators and repressors), and binding of regulatory proteins (transcription factors or repressors) to the promoter sequence of a gene resulting in activation or blocking of transcription. Furthermore, the activity of nonhistone proteins, such as transcription factors and repressors, can also be modulated by post-translational protein modifications (e.g., acetylation, phosphorylation or glycosylation), and these modifications could change protein conformation and lead to changes in activity.

As the variety of gene expression profiles is determined by distinct sets of transcriptional regulators (transcription factors or repressors) that control and determine which genes are switched on or off, HDACIs may upregulate or downregulate gene expression via altering the activity of transcription factors or repressors by post-translational modifications (PTMs) in our bladder tumor cells. Additionally, since the majority of cellular functions are carried out by proteins, HDACIs may modulate biological changes not only through alterations at 
the protein level but also by PTMs in bladder carcinoma cells. However, the role of the two newly identified histone markers (H2AK118ac and H2BK34ac) in the antitumor activity of HDACIs in bladder cancer, as well as the precise mechanism for how HDACIs upregulate or downregulate specific gene and protein expression through histone modifications and PTMs will require further investigation.

In summary, we have profiled the antitumor activity of HDACIs in association with enhanced lysine acetylation in histone and non-histone proteins as well as altered levels of chromatin modifying proteins in bladder cancer cells. Proteomic data analysis further revealed dysregulation of protein expression involved in multiple biological functions and cell death associated pathways in romidepsin and TSA treated 5637 cells. These results suggest that the antitumor effect of HDACIs in bladder carcinoma is mediated through modulation of these pathways by histone modifications and PTMs, leading to cancer cell growth arrest and cell death. Our findings may be helpful for developing HDCAIs in combination with other therapeutics targeted at modulating relevant cell death pathways or at inhibiting cell proliferation in tumors. Further studies are needed to investigate the anticancer activity of HDACIs in bladder cancer via the modulation of signaling pathways (e.g., PI3K-PTEN-mTOR pathway) (55) or the inhibition of regulatory enzymes in histone modifications and PTMs (56) influencing cell survival and death.

\section{Acknowledgements}

The present study was supported by the Intramural Research Program of the U.S. National Cancer Institute, the National Institutes of Health.

\section{References}

1. Siegel RL, Miller KD and Jemal A: Cancer statistics, 2016. CA Cancer J Clin 66: 7-30, 2016.

2. Kaufman DS, Shipley WU and Feldman AS: Bladder cancer. Lancet 374: 239-249, 2009.

3. Weintraub MD, Li QQ and Agarwal PK: Advances in intravesical therapy for the treatment of non-muscle invasive bladder cancer (Review). Mol Clin Oncol 2: 656-660, 2014.

4. Stenzl A, Cowan NC, De Santis M, Kuczyk MA, Merseburger AS, Ribal MJ, Sherif A and Witjes JA; European Association of Urology (EAU): Treatment of muscle-invasive and metastatic bladder cancer: Update of the EAU guidelines. Eur Urol 59 1009-1018, 2011

5. Marks P, Rifkind RA, Richon VM, Breslow R, Miller T and Kelly WK: Histone deacetylases and cancer: Causes and therapies. Nat Rev Cancer 1: 194-202, 2001.

6. Xu WS, Parmigiani RB and Marks PA: Histone deacetylase inhibitors: Molecular mechanisms of action. Oncogene 26: 5541-5552, 2007

7. Marks PA and Xu WS: Histone deacetylase inhibitors: Potential in cancer therapy. J Cell Biochem 107: 600-608, 2009.

8. Schrump DS: Cytotoxicity mediated by histone deacetylase inhibitors in cancer cells: Mechanisms and potential clinical implications. Clin Cancer Res 15: 3947-3957, 2009.

9. Nakagawa M, Oda Y, Eguchi T, Aishima S, Yao T, Hosoi F, Basaki Y, Ono M, Kuwano M, Tanaka M, et al: Expression profile of class I histone deacetylases in human cancer tissues. Oncol Rep 18: 769-774, 2007.

10. Zhang Z, Yamashita H, Toyama T, Sugiura H, Ando Y, Mita K, Hamaguchi M, Hara Y, Kobayashi S and Iwase H: Quantitation of HDAC1 mRNA expression in invasive carcinoma of the breast. Breast Cancer Res Treat 94: 11-16, 2005.
11. Marquard L, Poulsen CB, Gjerdrum LM, de Nully Brown P, Christensen IJ, Jensen PB, Sehested M, Johansen P and Ralfkiaer E: Histone deacetylase 1, 2, 6 and acetylated histone H4 in B- and T-cell lymphomas. Histopathology 54: 688-698, 2009.

12. Witt O, Deubzer HE, Milde T and Oehme I: HDAC family: What are the cancer relevant targets? Cancer Lett 277: 8-21, 2009.

13. Ozawa A, Tanji N, Kikugawa T, Sasaki T, Yanagihara Y, Miura N and Yokoyama M: Inhibition of bladder tumour growth by histone deacetylase inhibitor. BJU Int 105: 1181-1186, 2010.

14. Bolden JE, Peart MJ and Johnstone RW: Anticancer activities of histone deacetylase inhibitors. Nat Rev Drug Discov 5: 769-784, 2006.

15. Minucci S and Pelicci PG: Histone deacetylase inhibitors and the promise of epigenetic (and more) treatments for cancer. Nat Rev Cancer 6: 38-51, 2006.

16. Yoshida M, Kijima M, Akita M and Beppu T: Potent and specific inhibition of mammalian histone deacetylase both in vivo and in vitro by trichostatin A. J Biol Chem 265: 17174-17179, 1990.

17. Tan J, Cang S, Ma Y, Petrillo RL and Liu D: Novel histone deacetylase inhibitors in clinical trials as anti-cancer agents. J Hematol Oncol 3: 5, 2010.

18. McGraw AL: Romidepsin for the treatment of T-cell lymphomas. Am J Health Syst Pharm 70: 1115-1122, 2013.

19. Li QQ, Wang G, Liang H, Li JM, Huang F, Agarwal PK, Zhong Y and Reed E: $\beta$-Elemene promotes cisplatin-induced cell death in human bladder cancer and other carcinomas. Anticancer Res 33: 1421-1428, 2013.

20. Florens L, Carozza MJ, Swanson SK, Fournier M, Coleman MK, Workman JL and Washburn MP: Analyzing chromatin remodeling complexes using shotgun proteomics and normalized spectral abundance factors. Methods 40: 303-311, 2006.

21. Paoletti AC, Parmely TJ, Tomomori-Sato C, Sato S, Zhu D, Conaway RC, Conaway JW, Florens L and Washburn MP: Quantitative proteomic analysis of distinct mammalian Mediator complexes using normalized spectral abundance factors. Proc Natl Acad Sci USA 103: 18928-18933, 2006.

22. Ou JN, Torrisani J, Unterberger A, Provençal N, Shikimi K, Karimi M, Ekström TJ and Szyf M: Histone deacetylase inhibitor Trichostatin A induces global and gene-specific DNA demethylation in human cancer cell lines. Biochem Pharmacol 73: 1297-1307, 2007.

23. Swanton C: Cell-cycle targeted therapies. Lancet Oncol 5: 27-36, 2004.

24. Morgan DO: Principles of CDK regulation. Nature 374: 131-134, 1995.

25. Sherr CJ: Cancer cell cycles. Science 274: 1672-1677, 1996.

26. Dynlacht BD: Regulation of transcription by proteins that control the cell cycle. Nature 389: 149-152, 1997.

27. Wesierska-Gadek J, Gueorguieva M and Horky M: Dual action of cyclin-dependent kinase inhibitors: Induction of cell cycle arrest and apoptosis. A comparison of the effects exerted by roscovitine and cisplatin. Pol J Pharmacol 55: 895-902, 2003.

28. Parker LL, Sylvestre PJ, Byrnes MJ III, Liu F and PiwnicaWorms H: Identification of a 95-kDa WEE1-like tyrosine kinase in HeLa cells. Proc Natl Acad Sci USA 92: 9638-9642, 1995.

29. Mitra J and Enders GH: Cyclin A/Cdk2 complexes regulate activation of Cdk1 and Cdc25 phosphatases in human cells. Oncogene 23: 3361-3367, 2004.

30. Fisher DE: Apoptosis in cancer therapy: Crossing the threshold. Cell 78: 539-542, 1994.

31. Haldar S, Chintapalli J and Croce CM: Taxol induces bcl-2 phosphorylation and death of prostate cancer cells. Cancer Res 56 : 1253-1255, 1996

32. Blagosklonny MV, Schulte T, Nguyen P, Trepel J and Neckers LM: Taxol-induced apoptosis and phosphorylation of $\mathrm{Bcl}-2$ protein involves c-Raf-1 and represents a novel c-Raf-1 signal transduction pathway. Cancer Res 56: 1851-1854, 1996.

33. Blagosklonny MV, Giannakakou P, el-Deiry WS, Kingston DG, Higgs PI, Neckers L and Fojo T: Raf-1/bcl-2 phosphorylation: A step from microtubule damage to cell death. Cancer Res 57: 130-135, 1997.

34. Haldar S, Basu A and Croce CM: Bcl2 is the guardian of microtubule integrity. Cancer Res 57: 229-233, 1997.

35. Haldar S, Basu A and Croce CM: Serine-70 is one of the critical sites for drug-induced $\mathrm{Bcl} 2$ phosphorylation in cancer cells. Cancer Res 58: 1609-1615, 1998.

36. Chang BS, Minn AJ, Muchmore SW, Fesik SW and Thompson CB: Identification of a novel regulatory domain in Bcl-X(L) and Bcl-2. EMBO J 16: 968-977, 1997. 
37. Roos WP, Thomas AD and Kaina B: DNA damage and the balance between survival and death in cancer biology. Nat Rev Cancer 16: 20-33, 2016.

38. Friedberg EC, Walker GC, Siede W and Schultz RA: DNA Repair and Mutagenesis. 2nd edition. ASM Press, Washington, DC, 2006.

39. Halliwell B: Free radicals, antioxidants, and human disease: Curiosity, cause, or consequence? Lancet 344: 721-724, 1994.

40. Brot N, Weissbach L, Werth J and Weissbach H: Enzymatic reduction of protein-bound methionine sulfoxide. Proc Nat Acad Sci USA 78: 2155-2158, 1981.

41. Demple B and Linn S: 5,6-Saturated thymine lesions in DNA: Production by ultraviolet light or hydrogen peroxide. Nucleic Acids Res 10: 3781-3789, 1982

42. Xia T, Kovochich M, Brant J, Hotze M, Sempf J, Oberley T, Sioutas C, Yeh JI, Wiesner MR and Nel AE: Comparison of the abilities of ambient and manufactured nanoparticles to induce cellular toxicity according to an oxidative stress paradigm. Nano Lett 6: 1794-1807, 2006.

43. Feng R, Oton A, Mapara MY, Anderson G, Belani C and Lentzsch S: The histone deacetylase inhibitor, PXD101, potentiates bortezomib-induced anti-multiple myeloma effect by induction of oxidative stress and DNA damage. Br J Haematol 139: 385-397, 2007.

44. Rosato RR, Maggio SC, Almenara JA, Payne SG, Atadja P, Spiegel S, Dent P and Grant S: The histone deacetylase inhibitor LAQ824 induces human leukemia cell death through a process involving XIAP down-regulation, oxidative injury, and the acid sphingomyelinase-dependent generation of ceramide. Mol Pharmacol 69: 216-225, 2006.

45. Feng R, Ma H, Hassig CA, Payne JE, Smith ND, Mapara MY, Hager JH and Lentzsch S: KD5170, a novel mercaptoketonebased histone deacetylase inhibitor, exerts antimyeloma effects by DNA damage and mitochondrial signaling. Mol Cancer Ther 7: $1494-1505,2008$.

46. Rosato RR, Almenara JA, Maggio SC, Coe S, Atadja P, Dent P and Grant S: Role of histone deacetylase inhibitor-induced reactive oxygen species and DNA damage in LAQ-824/fludarabine antileukemic interactions. Mol Cancer Ther 7: 3285-3297, 2008 .
47. Orrenius S, Gogvadze V and Zhivotovsky B: Mitochondrial oxidative stress: Implications for cell death. Annu Rev Pharmacol Toxicol 47: 143-183, 2007.

48. Rao R, Nalluri S, Fiskus W, Savoie A, Buckley KM, Ha K, Balusu R, Joshi A, Coothankandaswamy V, Tao J, et al: Role of CAAT/enhancer binding protein homologous protein in panobinostat-mediated potentiation of bortezomib-induced lethal endoplasmic reticulum stress in mantle cell lymphoma cells. Clin Cancer Res 16: 4742-4754, 2010.

49. Rao R, Nalluri S, Kolhe R, Yang Y, Fiskus W, Chen J, Ha K, Buckley KM, Balusu R, Coothankandaswamy V, et al: Treatment with panobinostat induces glucose-regulated protein 78 acetylation and endoplasmic reticulum stress in breast cancer cells. Mol Cancer Ther 9: 942-952, 2010.

50. Kahali S, Sarcar B, Prabhu A, Seto E and Chinnaiyan P: Class I histone deacetylases localize to the endoplasmic reticulum and modulate the unfolded protein response. FASEB J 26: 2437-2445, 2012.

51. Yi C, Ma M, Ran L, Zheng J, Tong J, Zhu J, Ma C, Sun Y, Zhang S, Feng W, et al: Function and molecular mechanism of acetylation in autophagy regulation. Science 336: 474-477, 2012.

52. Hassler MR and Egger G: Epigenomics of cancer - emerging new concepts. Biochimie 94: 2219-2230, 2012

53. Jerónimo $\mathrm{C}$ and Henrique R: Epigenetic biomarkers in urological tumors: A systematic review. Cancer Lett 342: 264-274, 2014

54. Bannister AJ and Kouzarides T: Regulation of chromatin by histone modifications. Cell Res 21: 381-395, 2011.

55. Abbosh PH, McConkey DJ and Plimack ER: Targeting signaling transduction pathways in bladder cancer. Curr Oncol Rep 17: 58, 2015.

56. O'Rourke CJ, Knabben V, Bolton E, Moran D, Lynch T, Hollywood D and Perry AS: Manipulating the epigenome for the treatment of urological malignancies. Pharmacol Ther 138: 185-196, 2013. 